\title{
A study of overflow simulations using MPAS-Ocean: vertical grids, resolution, and viscosity
}

\author{
Shanon M. Reckinger ${ }^{\mathrm{a}}$, Mark R. Petersen ${ }^{\mathrm{b}}$, Scott J. Reckinger ${ }^{\mathrm{c}}$ \\ ${ }^{a}$ Fairfield University \\ School of Engineering, Department of Mechanical Engineering \\ 1073 North Benson Rd. \\ Fairfield, CT 06824 \\ ${ }^{b}$ Computer, Computational, and Statistical Sciences Division \\ Los Alamos National Laboratory \\ Los Alamos, NM 87545 \\ ${ }^{c}$ Brown University \\ Department of Earth, Environmental, and Planetary Sciences \\ Providence, RI 02912
}

\begin{abstract}
MPAS-Ocean is used to simulate an idealized, density-driven overflow using the dynamics of overflow mixing and entrainment (DOME) setup. Numerical simulations are carried out using three of the vertical coordinate types available in MPAS-Ocean, including z-star with partial bottom cells, z-star with full cells, and sigma coordinates. The results are first benchmarked against other models, including the MITgcm's z-coordinate model and HIM's isopycnal coordinate model, which are used to set the base case used for this work. A full parameter study is presented that looks at how sensitive overflow simulations are to vertical grid type, resolution, and viscosity. Horizontal resolutions with $50 \mathrm{~km}$ grid cells are under-resolved and produce poor results, regardless of other parameter settings. Vertical grids ranging in thickness from $15 \mathrm{~m}$ to $120 \mathrm{~m}$ were tested. A horizontal resolution of $10 \mathrm{~km}$ and a vertical resolution of $60 \mathrm{~m}$ are sufficient to resolve the mesoscale dynamics of the DOME configuration, which mimics real-world overflow parameters. Mixing and final buoyancy are least sensitive to horizontal viscosity, but strongly sensitive to vertical viscosity. This suggests that vertical viscosity could be adjusted in overflow water formation regions to influence mixing and product water characteristics. Lastly, the study shows that sigma coordinates produce much less mixing than z-type coordinates, resulting in heavier plumes that go further down slope. Sigma coordinate are less sensitive to changes in resolution but as sensitive to vertical viscosity compared to z-coordinates.
\end{abstract}

Keywords: dynamics of overflow mixing and entrainment (DOME), MPAS-Ocean, sigma vertical coordinate, z-star with partial bottom cells, model resolution

\section{Introduction}

Overflows are density driven currents that flow down topographical features and mix with the ambient ocean. Dense water forms for a variety of reasons including cooling, evaporation, and salt addition (due to brine rejection during ice formation). After the 
formation of the dense water, which typically occurs in a semi-enclosed region, it can flow down narrow straits or continental slopes until it reaches its neutral buoyancy level or the ocean bottom (Legg 2012). Examples of oceanic overflows include the Nordic deep overflows such as in the Denmark Strait (Girton and Sanford 2003; Käse et al. 2003) and Faroe Bank Channel (Mauritzen et al. 2005), Antarctic deep overflows such as from Weddell (Foster and Carmack 1976) and Ross seas (Gordon et al. 2004; Muench et al.|2009), and the intermediate subtropical overflows such as from the Red (Peters et al. 2005 ; Peters and Johns 2005 ; Baumert et al. 2005) and Mediterranean seas (Baringer and Price 1997).

These dense overflows affect the properties of intermediate and deep water and significantly influence large-scale ocean circulation(Legg et al. 2009). Climate models without accurate overflow representation may have incorrect heat transport distribution and incorrect magnitude and structure of their meridional overturning circulation (Legg et al. 2009). Even when the overflows are resolved in global ocean models, the mixing and entrainment processes are often not resolved and, thus, must be parameterized. The scales associated with the mixing due to overflows are on the order of minutes and meters (Ilicak et al. 2008). Additionally, most global ocean circulation models solve the hydrostatic primitive equations, so vertical mixing must be parameterized.

In global simulations using z-coordinate models, downslope flows have too much entrainment, which compromises simulations of the deep ocean (Roberts and Wood 1997; Winton et al. 1998; Wang et al. 2008). This spurious mixing is generated by the stair-step representation of the bottom topography, which can be reduced by using partial cells bottom cells (Adcroft et al. 1997), but not eliminated. The representation or parameterization of overflows remains difficult at horizontal resolutions coarser than a few kilometers (Legg et al. 2006; Snow et al. 2015). There have been schemes developed to eliminate spurious mixing as the plume descends the slope for z-coordinate models using various bottom-boundary layer models (CAMPIN and Goosse 1999; Beckmann and Döscher 1997; Killworth and Edwards 1999; Song and Chao 2000).

Terrain following coordinate models are well suited for overflows and often use turbulence closure models for mixing (Ezer and Mellor 2004; Ezer 2005; Ilicak et al. 2008). Also, terrain following coordinates are more commonly used for coastal and regional applications than global simulations due to their inherent horizontal pressure gradient errors (Blumberg and Mellor 1987; Haidvogel et al. 2000). Isopycnal models are also a natural fit for capturing overflow dynamics, however, they require an explicit diapycnal mixing scheme (Hallberg 2000; Papadakis et al. 2003; Legg et al. 2006). No mixing schemes or overflow parameterizations are used in this study, rather this study focuses on a characterization of numerical mixing.

The Dynamics of Overflows Mixing and Entrainment (DOME) is an initiative responsible for developing an idealized overflow test case that could be used to compare different ocean models' treatment of the overflow dynamics. This initiative was part of the Gravity Current Entrainment Climate Process Team (CPT; Legg et al. 2009). There have been other projects with similar goals of understanding the sensitivity of numerical choices in models looking at specific regions or dynamics. These include Dynamics of North Atlantic Models (DYNAMO; Meincke et al. 2001), Data Assimilation and Model Evaluation Experiments in the Gulf Stream region (DAMEE-GSR; Willems 1995), and Data Assimilation and Model Evaluation Experiments in the North Atlantic Basin (DAMEE-NAB; Chassignet et al. 2000). A direct 
consequence of various models and laboratory experiments studying the DOME test case (or something very similar) is, first, an improved description of the important physical processes that affect overflows. A second consequence is a deeper understanding of the sensitivity of overflow mixing to physical (inflow density anomaly, slope angle, ambient fluid stratification, etc., e.g. Cenedese et al. (2004); Legg et al. (2006)) and numerical parameters (resolution, vertical coordinate, subgrid-scale parameterizations, advection schemes, etc., e.g. Özgökmen and Chassignet (2002); Özgökmen et al. (2004a); Anderson (2004); Ezer and Mellor (2004); Ezer (2005); Legg et al. (2006); Legg et al. (2008); Wang et al. (2008); Laanaia et al. (2010); Bates et al. (2012)). In the DOME scenario, high resolution cases can be used as benchmarks, even across models.

Second, overflows can be represented with straightforward mathematical models that are used to set tracer diffusivity and eddy viscosity. The most commonly used parameterizations of this form include the K-profile parameterization (KPP, used in z-coordinate models) and the Turner-Ellison parameterization (TE, used in isopycnal coordinate models). In KPP, vertical mixing is parameterized by specifying vertical viscosity as a function of the local gradient Richardson number (Large et al. 1994; Large and Gent 1999).

The DOME configuration can be used to test overflow parameterizations by comparing high resolution models without mixing parameterizations to lower resolution models with parameterizations. Legg et al. (2006) was able to show that the Hallberg Isopycnal Model (HIM) compares well with high resolution (500 $\mathrm{m}$ in the horizontal), non-hydrostatic $\mathrm{z}^{-}$ coordinate (MITgcm) simulations. The HIM model was run at a horizontal resolution of $10 \mathrm{~km}$ using a modified Turner-Ellison parameterization (Turner 1986; Ellison and Turner 1959 ) for entrainment due to shear driven mixing based off of the local gradient Richardson number (Hallberg 2000) and the Hallberg Bottom Boundary Layer model to parameterize frictional mixing. Similarly, an idealized overflow configuration was used to test the HYCOM parameterization, which is derived from high resolution, non-hydrostatic simulations using Nek5000 (Xu et al. 2006). Ezer and Mellor (2004); Jackson et al. (2008); Ilicak et al. (2008); Ilicak et al. (2012) also used an idealized overflow domain to test new and existing parameterizations.

Over the past 10 years, there have been numerous studies on idealized overflow using different ocean models. Table 1 gives a summary of all those studies and categorizes them with respect to the model, vertical grid type, horizontal grid type, numerical differentiation scheme, the use of bottom drag, the advection scheme type, the mixing scheme type, and use of non-hydrostatic primitive equations. Additionally, the studies are categorized by whether or not they investigated the sensitivity of the DOME test case to various numerical parameters including: vertical and horizontal diffusivity, vertical and horizontal viscosity, and vertical and horizontal resolution. Table 2 provides more detail on the type of numerical parameters that were studied, but focuses on viscosity and resolution, since that is the focus of this paper. Even when looking at specific sensitivity studies, the parameters were tested in a variety of ways. Table 1 shows whether or not a sensitivity test was conducted for each parameter, indicated with a yes $(\mathrm{Y})$ or no $(\mathrm{N})$. The $\mathrm{Y}^{*}$ indicates that the parameter was varied, but under one of following constraints: (a) not independently with the variation of other parameters, (b) the sensitivity of its variation was not studied, or (c) a parameterization was used so it is not known exactly how the parameter varied.

All types of vertical coordinate models have been investigated using the DOME case 
including z-coordinate models (Ezer and Mellor 2004; Ezer 2005: Tseng and Dietrich 2006 Wang et al. 2008), z-coordinate with partial bottom cells (PBCs) (Legg et al.|2006 2008. Wang et al. 2008; Bates et al. 2012), sigma coordinate models (Ezer and Mellor 2004: Ozgökmen et al. 2004b; Ezer 2005; Wang et al. 2008), and isopycnal models (Legg et al. 2006 2008). In the majority of the cases where a parameter is varied and the rest of the parameters are held constant $(\mathrm{Y})$, the sensitivity study only included 2 or 3 different cases. For example, the first $Y$ that appears in the table is for Ezer (2005) under vertical diffusivity. However, Table 2 shows that only two cases are used to test the sensitivity of the vertical diffusivity (one with diffusivity equal to zero, and the other with nonzero diffusivity). One noticeably untested (or unreported) sensitivity test is the variation of vertical resolution, which no study has tested as an independent controlling factor of overflows within the DOME test case (most varied vertical and horizontal resolution simultaneously). Riemenschneider and Legg (2007) did test vertical resolution dependence on overflows as an independent controlling factor in the Faroe Bank Channel. Laanaia et al. (2010) also tested vertical resolution dependence independently using sigma coordinates in the NEMO-OPA9 model. They found that overflow dynamics were incredibly sensitive to vertical resolution and adding merely 5 sigma levels in the bottom boundary layer significantly improved overflow representation.

Horizontal resolution has been tested frequently, but it is commonly tested in only one of the vertical coordinate types (Ezer and Mellor 2004; Legg et al. 2006), for only two horizontal resolutions (Bates et al. 2012), while also varying vertical resolution (Ezer and Mellor 2004; Ezer 2005; Legg et al. 2006; Tseng and Dietrich 2006; Wang et al.|2008), or while also varying viscosity (Ezer 2005; Legg et al. 2006; Wang et al.|2008). The story is similar for the other numerical parameters. In particular, Legg et al. (2008) looked at the MITgcm sensitivity to vertical and horizontal viscosity, but only at one horizontal and vertical resolution, for a smaller set of viscosities than the set of numerical experiments presented in this paper, and only for the z-coordinate model.

The goal of this paper is twofold: (a) to validate MPAS-Ocean, as it is a new ocean model, by testing it on a well known benchmark problem, and (b) to conduct a full numerical parameter study on the DOME setup that brings together and fills in some of the missing pieces from all of the previous studies. In particular, this work contributes to previous work by covering a more expansive range of parameter space than has been previously done, and also by investigating the sensitivity to vertical resolution as an independent controlling factor of overflows within the DOME test case. None of the models run for this study have explicit mixing schemes or overflow parameterizations. The goal is to study a characterization of numerical mixing, since MPAS-Ocean will be primarily run in z-coordinate mode. Additionally, the sigma coordinate simulations are done for comparison, so no parameterizations are used there either.

The paper is organized as follows: Section 2 describes MPAS-Ocean and the experimental setup; Section 3 describes the analysis techniques used for understanding overflows; Section 4 presents the model configuration to ensure that MPAS-Ocean correctly simulates the DOME test case; Section 5 reports the results from a sensitivity study on vertical viscosity, horizontal viscosity, vertical resolution, and horizontal resolution for z-star, z-star with PBCs, and sigma vertical coordinate configurations; and Section 6 summarizes results and provides a recommendation for the most computationally cost effective option for global circulation models. 
Table 1: Summary of models that have tested DOME

\begin{tabular}{|c|c|c|c|c|c|c|c|c|c|c|c|c|c|c|}
\hline Study & Model & 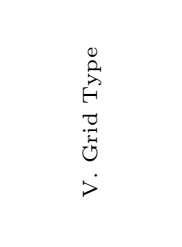 & 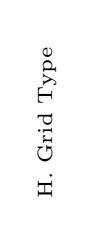 & 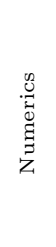 & 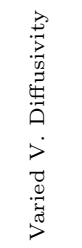 & 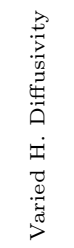 & 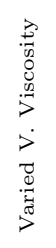 & 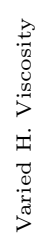 & 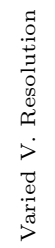 & 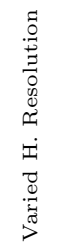 & 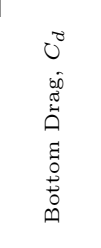 & 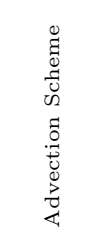 & 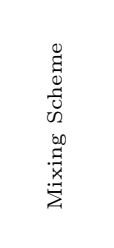 & 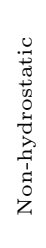 \\
\hline Ezer and Mellor 2004 & POM & $\mathrm{z}, \sigma$ & $\mathrm{C}$ & I & $\mathrm{Y}^{*}$ & $\mathrm{Y}^{*}$ & $\mathrm{Y}^{*}$ & $\mathrm{Y}^{*}$ & $\mathrm{Y}^{*}$ & $\mathrm{Y}^{*}$ & $\mathrm{~N} / \mathrm{A}$ & MP & M-Y & $\mathrm{N}$ \\
\hline Özgökmen et al. $(2004 \mathrm{~b})^{\dagger}$ & Nek5000 & $\sigma$ & hex-A & II & $\mathrm{N}$ & $\mathrm{N}$ & $\mathrm{N}$ & $\mathrm{N}$ & $\mathrm{N}$ & $\mathrm{N}$ & $\mathrm{N} / \mathrm{A}$ & $\mathrm{PQ}$ & none & $\mathrm{Y}$ \\
\hline Ezer $(2005)$ & POM & $\mathrm{z}, \sigma$ & $\mathrm{C}$ & $\mathrm{I}$ & $\mathrm{Y}$ & $\mathrm{Y}$ & $\mathrm{Y}^{*}$ & $\mathrm{Y}^{*}$ & $\mathrm{Y}^{*}$ & $\mathrm{Y}$ & $\mathrm{N} / \mathrm{A}$ & MP & M-Y & $\mathrm{N}$ \\
\hline Legg et al. $(2006)$ & MITgcm & zp (low rez*) & $\mathrm{C}$ & III & $\mathrm{N}(0)$ & $\mathrm{N}(0)$ & $\mathrm{Y}^{*}$ & $\mathrm{Y}^{*}$ & $\mathrm{Y}^{*}$ & $\mathrm{Y}$ & 0.002 & $\mathrm{~S}$ & none & $\mathrm{N}$ \\
\hline Legg et al. $(2006)$ & MITgcm & zp (high rez*) & $\mathrm{C}$ & III & $\mathrm{N}(0)$ & $\mathrm{N}(0)$ & $\mathrm{N}$ & $\mathrm{N}$ & $\mathrm{N}$ & $\mathrm{N}$ & 0.002 & $\mathrm{~S}$ & none & $\mathrm{Y}$ \\
\hline Legg et al. $(2006)$ & HIM & $\rho$ & $\mathrm{C}$ & $\mathrm{I}$ & $\mathrm{N}$ & $\mathrm{N}$ & $\mathrm{Y}^{*}$ & $\mathrm{Y}^{*}$ & $\mathrm{~N}$ & $\mathrm{Y}$ & 0.002 & $\mathrm{~B}$ & $\mathrm{TP}$ & $\mathrm{N}$ \\
\hline Tseng and Dietrich (2006) & DieCAST & $\mathrm{z}$ & $\mathrm{A}-\mathrm{C}$ & $\mathrm{I}$ & $\mathrm{Y}^{*}$ & $\mathrm{Y}^{*}$ & $\mathrm{Y}^{*}$ & $\mathrm{Y}^{*}$ & $\mathrm{Y}^{*}$ & $\mathrm{Y}$ & 0.002 & $4 \mathrm{O}, 2 \mathrm{O}$ & MR & $\mathrm{N}$ \\
\hline Legg et al. $(2008)$ & MITgcm & $\mathrm{zp}$ & $\mathrm{C}$ & III & $\mathrm{N}$ & $\mathrm{N}$ & $\mathrm{Y}$ & $\mathrm{Y}$ & $\mathrm{N}$ & $\mathrm{N}$ & 0.002 & $\mathrm{~S}, \mathrm{O}, \mathrm{P}$ & $\mathrm{N}$ & $\mathrm{N}$ \\
\hline Legg et al. 2008 & HIM & $\rho$ & $\mathrm{C}$ & $\mathrm{I}$ & $\mathrm{N}$ & $\mathrm{N}$ & $\mathrm{N}$ & $\mathrm{N}$ & $\mathrm{N}$ & $\mathrm{N}$ & 0.002 & $\mathrm{~B}$ & TP,JHP & $\mathrm{N}$ \\
\hline Wang et al. 2008 & FEOM & $\mathrm{z}, \mathrm{zp}, \sigma$ & tri-A & IV & $\mathrm{Y}$ & $\mathrm{Y}^{*}$ & $\mathrm{~N}$ & $\mathrm{Y}$ & $\mathrm{N}$ & $\mathrm{Y}$ & 0.002 & FCT & $\mathrm{MR}$ & $\mathrm{N}$ \\
\hline Bates et al. $(2012$ & MOM & $\mathrm{zp}$ & $\mathrm{B}$ & $\mathrm{I}$ & $\mathrm{N}(0)$ & $\mathrm{N}$ & $\mathrm{N}$ & $\mathrm{Y}$ & $\mathrm{N}$ & $\mathrm{Y}$ & varied & MD & $\mathrm{SM}$ & $\mathrm{N}$ \\
\hline this study & MPAS-Ocean & $\mathrm{z}^{*}, \mathrm{z}^{*} \mathrm{p}, \sigma$ & hex-C & III & $\mathrm{N}(0)$ & $\mathrm{N}(0)$ & $\mathrm{Y}$ & $\mathrm{Y}$ & $\mathrm{Y}$ & $\mathrm{Y}$ & 0.002 & FCT & none & $\mathrm{N}$ \\
\hline \multicolumn{15}{|c|}{$\begin{array}{l}\text { Key: In first column, }\left({ }^{\dagger}\right) \text { indicates that the study did not utilize the DOME setup exactly. For V. Grid Type, zp means z-level with PBCs. H. } \\
\text { Grid Types are listed as either structured Arakawa grids (A-C), or unstructured grids (hex, tri, etc.). Please note that not all grids were uniform, } \\
\text { evenly spaced points in both the vertical and horizontal. Numerics indicate how differentiation is done, I- Finite Differences, II-Spectral } \\
\text { Elements, III-Finite Volume, IV-Finite Element. Y/N answers indicate where or not the study varied that parameter (Y) or held it constant } \\
\text { throughout all test runs (N). N(0) means zero diffusion was used in all cases. The Y* indicates that either the parameter was varied but not } \\
\text { independently, the sensitivity of its variation was not studied, or a parameterization was used. Advection schemes: MP-MPDATA, PQ-Pointwise } \\
\text { Quadrature, S-Superbee, 4O-4th order, 2O-2nd order, O-OS7MP, P-Prather, B-Bott's, FCT-Flux Corrected Transport, MD-multi-dimensional } \\
\text { piecewise parabolic method. Mixing Schemes: M-Y-Mellor, TP-Turner Parameterization, Yamada, JHP-Jackson and Hallberg scheme, } \\
\text { MR-modified Ri-dependent scheme, SM-Smagorinsky friction scheme. *MITgcm high resolution simulations of } 2.5 \text { km and finer used a stretched, } \\
\text { non-uniform grid with higher resolution in the embayment. }\end{array}$} \\
\hline
\end{tabular}

\section{Numerical Setup}

\subsection{About the model: MPAS-Ocean}

The model used in this work is MPAS-Ocean (Ringler et al. 2013). MPAS is an acronym for Model for Prediction Across Scales and is a software framework for climate model components developed by Los Alamos National Laboratory and the National Center of Atmospheric Research. Numerous cores have been developed within the MPAS framework, including a shallow-water model (Ringler 2011), a hydrostatic atmosphere model (Rauscher et al. 2013), a non-hydrostatic atmosphere model (Skamarock et al. 2012), a hydrostatic ocean model (Ringler et al. 2013), and sea-ice and land-ice models (under development).

The MPAS approach uses a horizontally conforming mesh that is a high-quality, easy-toconstruct, and multi-resolution tessellation (Ringler et al. 2008). Here high-quality means that the mesh size varies smoothly and each polygon has nearly uniform edge lengths. Easyto-construct means that fast algorithms exist to create the meshes. The preference is to use Spherical Centroidal Voronoi Tessellations (SCVTs), which are n-sided polygons, but in practice mostly hexagons. SCVTs are very convenient for variable resolution meshes because they are constructed from a mesh density function, and the mesh quality remains high as the number of points increases. The isotropy of a hexagon is also preferred over a quadrilateral or triangle. In the study presented here, the horizontal grids are all uniform (not using multi-resolution capabilities) in order to isolate parameter changes, especially to compare to other models. When SCVTs are used, they are referred to as a hex grid throughout. All cases in this work were run on a hex grid, unless noted otherwise.

The vertical grid uses the Arbitrary Lagrangian-Eulerian (ALE) method, which allows for a variety of vertical coordinate options (Petersen et al. 2015). These options include: z-level, 
Table 2: Summary of Work with DOME

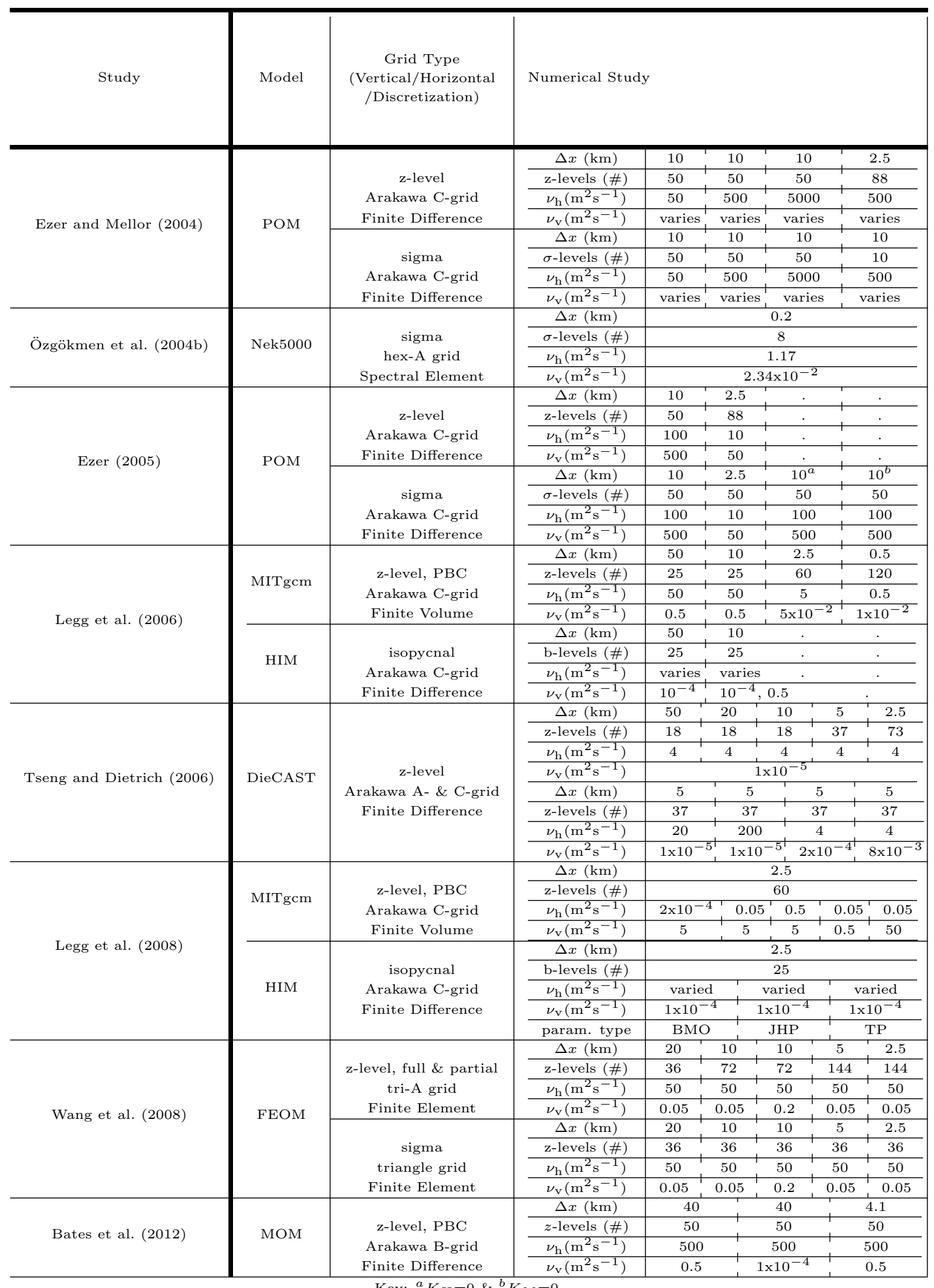

Key: ${ }^{a} K_{H}=0 \&{ }^{b} K_{M}=0$. 
where all layers have fixed thickness except for the top layer; z-star, where all layer thicknesses compress in proportion to the sea surface height (Adcroft and Campin 2004); sigma, where all layers are used and layers contract to follow bottom bathymetry (i.e. no vacant land cells at the bottom of the column); z-tilde, where thicknesses respond to high-frequency oscillations in a Lagrangian manner (Leclair and Madec 2011); and idealized isopycnal, which has no vertical transport between layers. In the simulations presented here, z-level, z-star, and sigma vertical coordinates are tested. Additionally, partial bottom cells can be used, which has been shown to be important for representing overflows (Adcroft et al. 1997).

The numerical methods used by MPAS-Ocean include a finite-volume discretization of the primitive equations using a C-grid staggering in the horizontal (Thuburn et al. 2009; Ringler et al. 2010), a split-explicit time stepping algorithm (Higdon 2005), and a fluxcorrected transport (FCT) tracer advection scheme that is quasi third-order and monotonic (Skamarock and Gassmann 2011). For more specific details on the MPAS-Ocean numerics, see Ringler et al. (2013).

\subsection{Test Case: DOME}

Fig. 1 shows the domain used. Dense water enters the domain at the embayment in the northern end. The inflow condition is discussed in Section 4 , but was verified to match Legg et al. (2006) at the $2.5 \mathrm{~km}$ resolution. The domain spans $2000 \mathrm{~km}$ in the $\mathrm{x}$-direction, $800 \mathrm{~km}$ in the y-direction, and $3600 \mathrm{~m}$ in the z-direction. The embayment is $100 \mathrm{~km}$ across, $50 \mathrm{~km}$ long, and $600 \mathrm{~m}$ deep. The physical parameters are set according to the reference case (Case 1) of Legg et al. (2006). This corresponds to an inflow density anomaly of $\Delta b_{0}=0.019 \mathrm{~ms}^{-2}$, an inflow flux of $8.64 \times 10^{6} \mathrm{~m}^{3} \mathrm{~s}^{-1}$, an ambient stratification of $N=2.3 \times 10^{-3} \mathrm{~s}^{-1}$, a Coriolis parameter of $f_{0}=1 \times 10^{-4} \mathrm{~s}^{-1}$, and topographic slope angle of $\tan (\alpha)=0.01$. The ambient stratification parameter corresponds to a background temperature stratification defined by

$$
T(z)=\frac{N^{2} \rho_{\mathrm{ref}}}{g \alpha_{t}} z+T_{\mathrm{ref}}
$$

where $T_{\text {ref }}=15^{\circ} \mathrm{C}, \rho_{\text {ref }}=1029.2 \mathrm{kgm}^{-3}, g=9.81 \mathrm{~ms}^{-2}$, and $\alpha_{t}=0.2 \mathrm{~kg} /\left(\mathrm{m}^{3} \mathrm{~K}\right)$. The vertical coordinate is defined at the surface as $z=0$ and is positive in the upwards direction. The inflow density anomaly parameter corresponds with an inflow temperature defined by

$$
T_{\text {inflow }}=-\frac{\Delta b_{0} \rho_{\text {ref }}}{g \alpha_{t}}+T_{\text {ref }}
$$

This results in a linear temperature profile that ranges from $5^{\circ} \mathrm{C}$ at $\mathrm{z}=-3600 \mathrm{~m}$ and $15^{\circ} \mathrm{C}$ at the surface with an inflow temperature of $5^{\circ} \mathrm{C}$. A passive tracer is introduced, with $\tau=0$ initially throughout the domain, and $\tau=1$ in the inflow water. Bottom drag is used with a drag coefficient of $C_{d}=0.002$. Vertical and horizontal tracer diffusivity are both set to zero. Salinity is constant, and a linear equation of state is used, where $\alpha_{t}$ is the thermal expansion coefficient. The inflow occurs on the northern wall of the embayment, in the bottom west corner of the wall, as specified in Legg et al. (2006). To prevent large increases in the sea surface height, an outflow condition is applied to the western wall, where the water volume added at the inflow is removed from the domain. The outflow flux is distributed equally across the entire western boundary. It was verified that the domain-averaged sea surface 


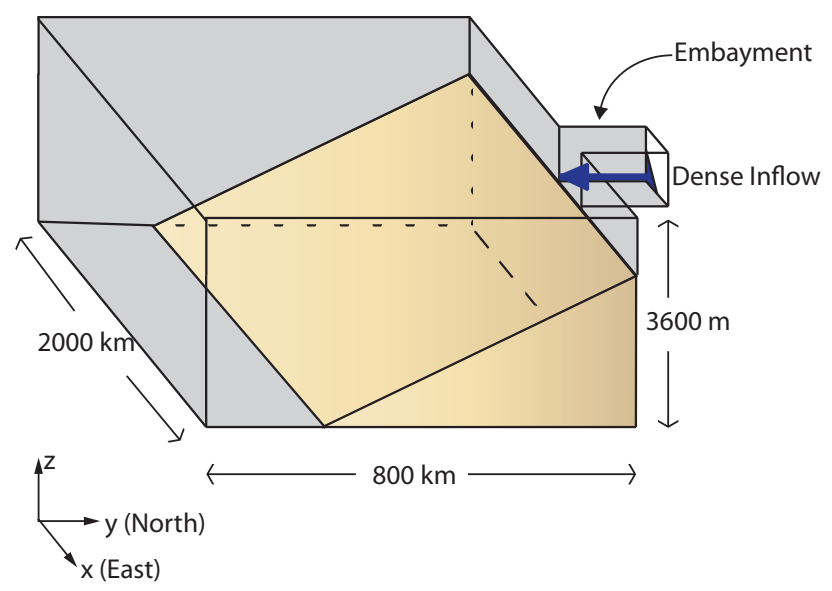

Figure 1: A schematic showing the DOME domain.

height remains constant to within $0.02 \mathrm{~m}$ after 40 days. The remaining walls have a no-flux boundary condition, and all walls are no-slip.

The full range of DOME parameters and overall dimensions of the domain are chosen to cover the values typical of the Denmark Strait Overflow, the Mediterranean Outflow, the Red Sea Outflow, and some of the Antarctic overflows (Legg et al. 2006). The most significant simplifications made in the idealized system are the use of linear stratification and the topographic profiles. However, observational measurements made by Girton and Sanford (2003) from the Denmark Strait Overflow can be used as a rough estimate. Legg et al. (2006) compared different cases (with different physical parameters, such as slope angle, stratification, inflow density, etc.) to the observations made with Girton and Sanford (2003). It was found that rate of plume descent, the downstream change in plume density, and the entrainment velocity all matched reasonably well when the differences in the idealized setup versus the observations were taken into account.

Since the physical parameters used in this work roughly compare to the Denmark Strait, the observed thickness of the Denmark Strait can be used as a rough estimate of the resolution requirements . According to Winton et al. (1998), the requirements for z-coordinate models using full cells to transport dense overflow without excess entrainment are $d x<h / \tan (\alpha)$ and $d z<h$, where $h$ is the thickness of the overflow plume and $\alpha$ is the topographic slope. The observed thickness of the Denmark Strait overflow is $160 \mathrm{~m}$. Therefore, the conditions require $d x<16 \mathrm{~km}$ and $d z<160 \mathrm{~m}$. If we provide five grid cells to span this length, then a satisfactory grid uses $d x=3.2 \mathrm{~km}$ and $d z=32 \mathrm{~m}$. This study explores the DOME system at the following resolutions: $d x=50,25,10$, and $2.5 \mathrm{~km}$ and $d z=120,60,30$, and $15 \mathrm{~m}$. Therefore, the investigation includes cases where the resolution requirements are met, and others that do not satisfy the conditions.

\subsection{Brief Description of Experiments}

Section 4 describes a series of experiments that not only validates MPAS-Ocean against other models, but also determines a base case. Numerical experiments were done to perform the following studies: inflow conditions (Section 4.2); vertical viscosity, horizontal viscosity, 
and vertical grid type (Section 4.4); and finally a direct comparison to MITgem and HIM (Section 4.5).

Section 5 describes the large set of experiments that are necessary in order to investigate the sensitivity of the overflow system on various numerical parameters, including vertical parameters (viscosity and resolution, Section 5.1), horizontal parameters (viscosity and resolution, Section 5.2), and vertical grid type (Section 5.3). A summary of these experiments can be found in Table 4. In all comparisons, all other parameters are held constant to isolate the effect of a single parameter. Additional comparisons are done to look at the dependence on the grid Reynolds number.

\section{Analysis}

\subsection{Two-dimensional Visualization Metrics}

In order to make a fair comparison across vertical resolutions, grid types, and partial bottom cells, the bottom tracer concentration is computed across a uniform thickness, $\Delta z_{\text {plot }}$, as

$$
\tau_{\text {bottom }}(x, y)=\frac{\int_{z_{\text {bot }}}^{z_{b o t}+\Delta z_{p l o t}} \tau(x, y, z) d z}{\Delta z_{\text {plot }}}
$$

where $z_{b o t}(x, y)$ is the z-coordinate of the bottom topography. Previous studies employing the DOME test case plotted tracer concentration in the deepest cell only. This caused striping in the y-direction in our simulations with high vertical resolution and partial bottom cells. In all plots in this paper, concentrations below a cut-off of 0.01 are white, and land cells near the northern wall are shown in gray.

The plume thickness,

$$
\delta_{P}(x, y)=\int_{\tau>0.01} d z,
$$

is simply the vertical extent of the plume envelope, defined by a boundary of $1 \%$ tracer concentration. It is particularly useful for visualizing columnar vortices in three dimensions. The test case used in this study is equivalent to Case 1 from Legg et al. (2006), which is the most commonly used case in other studies as well (Ezer 2005; Tseng and Dietrich 2006; Wang et al. 2008). This test case is classified to be in the "eddy regime" based on the classifications determined by Cenedese et al. (2004). Therefore, this metric is able to capture these three-dimensional eddy features (Fig. 2).

The plume height,

$$
h(x, y)=\frac{\int\left(z-z_{b o t}(x, y)\right) \tau(x, y, z) d z}{\int \tau(x, y, z) d z},
$$

is the tracer-weighted average distance of the plume above the bottom topography. For example, for a 100m-thick plume with constant $\tau$ traveling along the bottom topography, the plume height is $50 \mathrm{~m}$. In practice, this is a discrete summation over cells in a column, where $z$ is the $\mathrm{z}$-coordinate of the middle of the cell. Plots of plume height portray the vertical distribution of the plume in $(x, y)$ space. It is another way to see three-dimensional features in a two-dimensional plot. In particular, the plume edge where there is high eddy activity becomes apparent (Fig. 2). 


\subsection{One-Dimensional Analysis}

As was done in Legg et al. (2006) and various studies thereafter, the following metrics are used, especially for comparison between cases and comparison to other models. The plume path,

$$
Y(x)=\frac{\iint y \tau(x, y, z) d z d y}{\iint \tau(x, y, z) d z d y}
$$

is the tracer-weighted plume path in $y$. These integrals are computed over the full domain in $y$ and $z$. All 1D metrics presented in this study are time-averaged over the period of 22-40 days. This metric simplifies the results by giving an approximate path of the plume in one-dimensional space. The plume buoyancy,

$$
\bar{b}(x)=\frac{\iint b(x, y, z) \tau(x, y, z) d z d y}{\iint \tau(x, y, z) d z d y},
$$

is the tracer-weighted plume buoyancy, where $b=g\left(\rho_{\text {ref }}-\rho\right) / \rho_{\text {ref }}$. This is the mean buoyancy of the overflow water as a function of along-slope distance. For all the plots of plume buoyancy in the paper, $\bar{b}(x)$ is normalized as $\Delta b /\left|\Delta b_{0}\right|$, where $\Delta b=\left(\bar{b}-b_{\text {ref }}\right), \Delta b_{0}=$ $0.019 \mathrm{~ms}^{-2}, b_{\text {ref }}=0$ since buoyancy and density are both referenced to their surface values, and $\rho_{\text {ref }}=1029 \mathrm{~kg} / \mathrm{m}^{3}$.

Entrainment and mixing are analyzed by looking at the transport within the plume in the along-slope direction, defined by

$$
T(x)=\int_{A} U(x, y, z) d y d z,
$$

where $A$ is the $y-z$ cross-section where $\tau>0.01$, and $U$ is the zonal (eastward) velocity. The entrainment coefficient, (Legg et al. 2006),

$$
\alpha_{E}(x)=\frac{\frac{d T(x)}{d x} / L(x)}{T(x) / A(x)}
$$

is a dimensionless measure of the flux of water entering (positive $\alpha_{E}$ ) or exiting (negative $\alpha_{E}$ ) the plume envelope. Here $L$ is the length of the interface between overflow water $(\tau>0.01)$ and ambient water in the $(y, z)$ plane, approximated as the length of the plume across the slope in $y$, at each $x$ location. The entrainment coefficient is the ratio of the average velocity across the plume envelope to the average velocity through the cross-section within the envelope. In other words, the ratio of velocities entering versus traveling through the plume. At high horizontal resolutions, eddies make $L$ and $A$ highly variable in $x$, so the entrainment coefficient is smoothed with an averaging window of 8 points before plotting.

We introduce two new metrics that were not used by Legg et al. (2006) and others. The mean plume thickness is the plume thickness (Equation 4) averaged again in the y-direction,

$$
\delta_{P}(x)=\frac{\iint_{\tau>0.01} d z d y}{\int d y}
$$

Similarly, the mean plume height is computed by integrating the plume height (Equation 5) in $y$,

$$
h(x)=\frac{\iint\left(z-z^{b o t}(x, y)\right) \tau(x, y, z) d z d y}{\iint \tau(x, y, z) d z d y} .
$$




\subsection{Scalar Metric Analysis}

Additionally, the initial angle of descent is used as a scalar metric to compare cases and is defined as

$$
\theta=\frac{\Delta y^{*}}{\Delta x^{*}},
$$

where $x^{*}$ and $y^{*}$ represent the best-fit line for the plume path $(x, Y)$ from $x=-100 \mathrm{~km}$ to $0 \mathrm{~km}$. Thus, the initial angle of descent is actually the slope of the best-fit line. When $\theta=0$ the plume runs parallel to the slope (westward) and when $\theta=1$ the plume travels to the southwest at $45^{\circ}$. Lastly, the mean final buoyancy of the plume is calculated by finding the mean plume buoyancy from Equation 7 . The mean is computed from the mean plume buoyancy values located west of $x=-200 \mathrm{~km}$. Initial angle of descent and final mean buoyancy provide scalar metrics that are useful for comparing a large number of cases at once.

\section{Model Configuration}

\subsection{A Qualitative Look at an Overflow}

Fig. 2 shows various snapshots from the base case simulation, which will be described in greater detail in Sections 4.2 - 4.5 and Table 4. The expected qualitative features of idealized overflows are present. First, the plume descends the slope and is deflected along the slope to the west, due to the Coriolis effect. Second, there are large eddies that grow in amplitude throughout the simulation. These are most easily seen in plots of plume thickness and temperature and agree with previous work (Cenedese et al. 2004; Ezer and Mellor 2004; Legg et al. 2006: Wang et al. 2008). According to the classifications of Cenedese et al. (2004), this chosen set of physical parameters seems to fit in the "Eddy Regime", which is reasonable since the Froude number is one. Vertical water columns can be seen above each eddy, as was found in von Appen et al. (2014). Therefore, plume thickness can be used as a measure of eddy strength. The stronger the eddy, the thicker the vertical column of tracer will be. When looking at 2D plots of plume thickness, the eddy strength will be deduced by the magnitude of the plume thickness and the eddy size is approximated by the extent of the circle made up by the column of tracer. Although the strength of the eddy and thickness of the column vary by the numerical parameters used, the thickness can be as high as 2000 $\mathrm{m}$ (the vertical domain is 3600 at the deepest). Thus, these eddies are mostly barotropic, spanning almost the entirety of the water column, as was found in Lane-Serff and Baines (1998). The tracer concentration of the inflow water is one, and the ambient water is zero. As the plume descends from the embayment, ambient water is entrained, so that the plume expands and the tracer concentration drops. Entrainment occurs at the boundary at the top and sides of the plume, as seen by the envelope of blue around the green in Figs. 2 a and b.

\subsection{Inflow Conditions}

The inflow condition is set based on the analytic representation described by Legg et al. (2006), Equations 3-8. Their inflow was chosen so that it satisfied the following: it is in geostrophic balance, has a maximum Froude number of 1, and has a gradient Richardson number that is everywhere locally greater than $1 / 3$ (to minimize mixing in the embayment). 


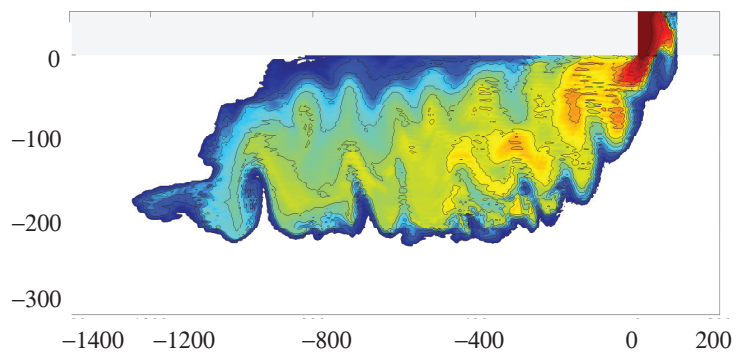

(a) bottom tracer concentration $\Delta \mathrm{z}_{\text {plot }}=60 \mathrm{~m}$

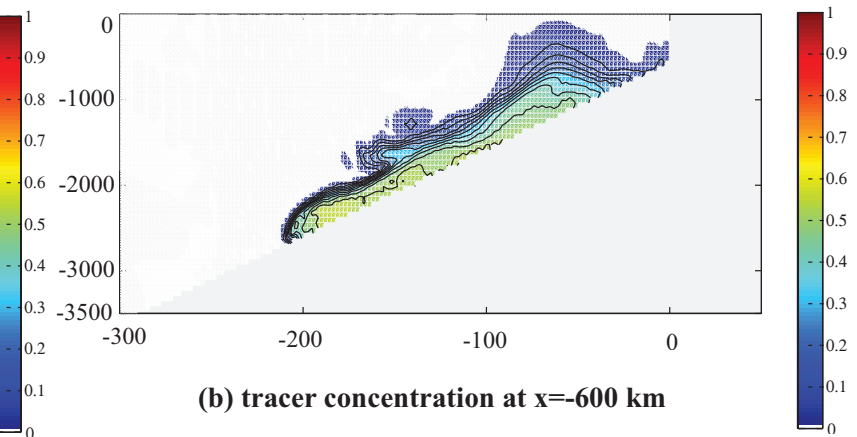

(b) tracer concentration at $x=-600 \mathrm{~km}$

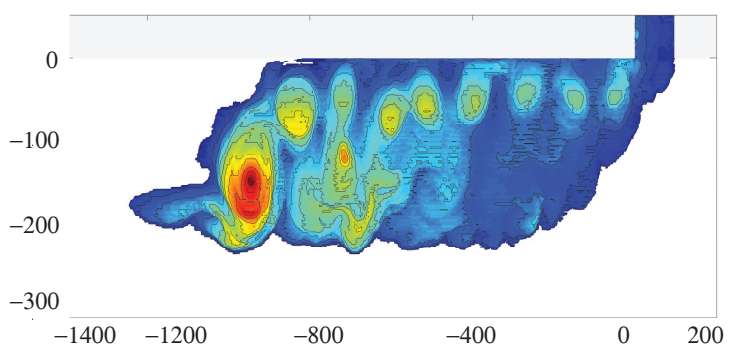

(c) plume thickness

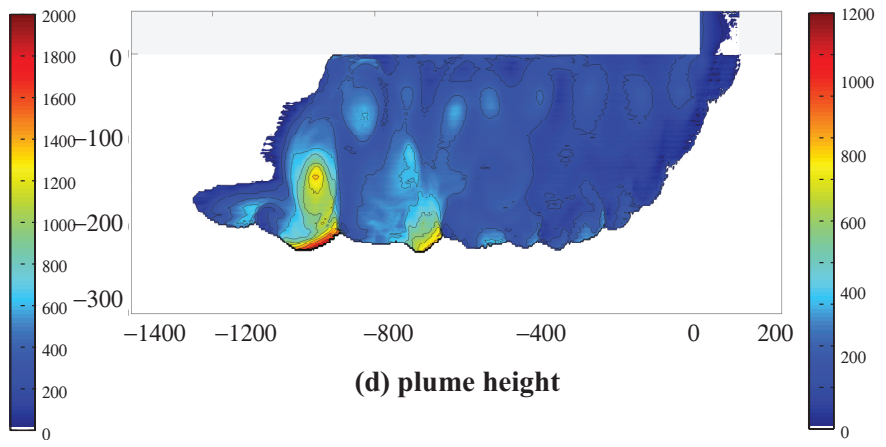

Figure 2: Images of base case at 40 days, with a horizontal resolution of $2.5 \mathrm{~km}$ and $d z=60 \mathrm{~m}$ using z-star PBC.

In order to compare directly with the MITgcm simulations, the inflow flux in the experiments presented here is calibrated to produce the same volumetric flux as the MITgcm simulations at the $2.5 \mathrm{~km}$ resolution. Regardless of resolution (horizontal or vertical) or vertical coordinate type, all cases have the same inflow volumetric flux of $8.64 \times 10^{6} \mathrm{~m}^{3} \mathrm{~s}^{-1}$.

A sensitivity study is performed, which shows that the results are largely insensitive to the inflow rate, in both qualitative 2D comparisons (not shown) and 1D metrics such as plume path and plume buoyancy (Fig. 3). This is similar to the findings in Riemenschneider and Legg (2007), where they report that variations in inflow forcing show only a very minor effect on mixing.

Fig. 3 shows four of the 1D metrics for simulations with four different inflow rates. Whereas plume path and plume buoyancy appear unaffected by the inflow condition, transport is directly proportional to the inflow rate. Overall, results are insensitive to inflow changes of 10-20\%. Mean plume thickness is reduced for only the case with the lowest inflow rate, which is likely due to a reduction in turbulent mixing. 


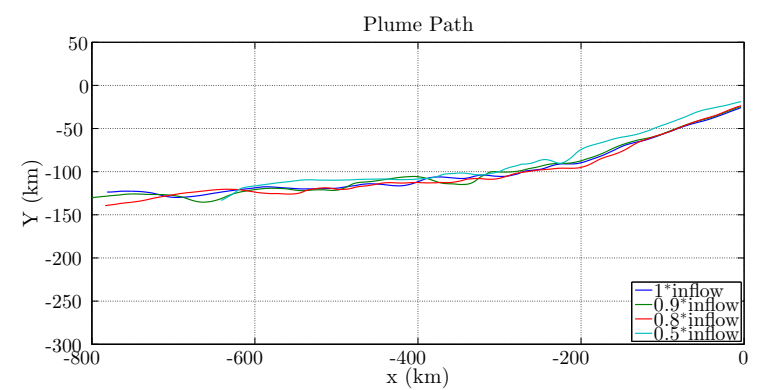

(a)

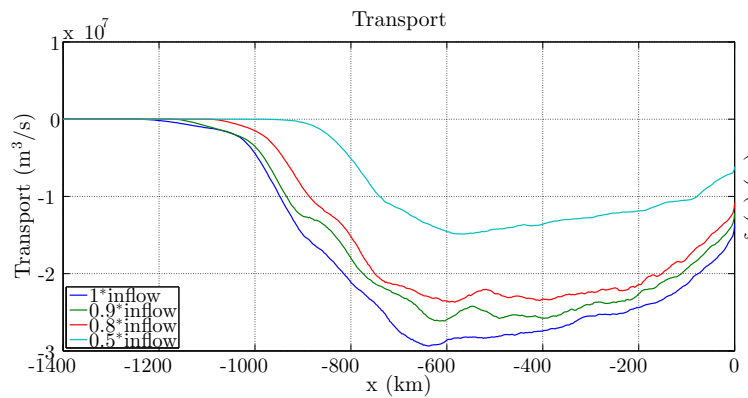

(c)

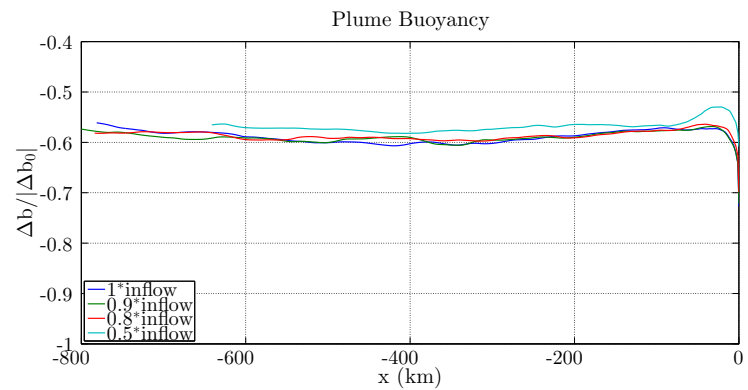

(b)

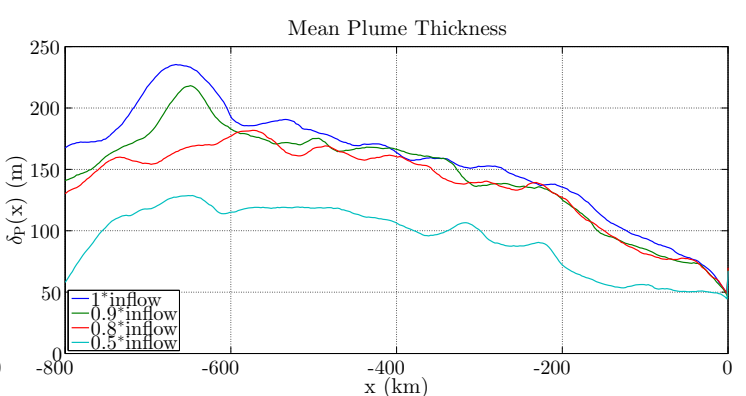

(d)

Figure 3: Plume path, plume buoyancy, transport, and mean plume thickness for the base case using four different inflow rates (full inflow, $90 \%, 80 \%$, and $50 \%$ of inflow). These cases are run with $d x=2.5 \mathrm{~km}$ and $d z=60 \mathrm{~m}$ and metrics are time averaged from day 22 to day 40. 
Table 3: Time steps (seconds) used for all simulations.

\begin{tabular}{|c|c|c|c|c|c|c|c|c|}
\hline Horizontal Resolution $\rightarrow$ & \multicolumn{2}{|c|}{$2.5 \mathrm{~km}$} & \multicolumn{2}{|c|}{$10 \mathrm{~km}$} & \multicolumn{2}{|c|}{$25 \mathrm{~km}$} & \multicolumn{2}{|c|}{$50 \mathrm{~km}$} \\
\hline Vertical Resolution $\downarrow$ & & & & & $z^{*}$ & & $z^{*}$ & \\
\hline $120 \mathrm{~m}$ (30 layers) & 60 & 60 & 240 & 240 & $\mathrm{NA}$ & NA & 600 & 600 \\
\hline 60m (60 layers) & 60 & 60 & 240 & 240 & 300 & NA & 600 & 300 \\
\hline $30 \mathrm{~m}$ (120 layers) & 60 & 15 & 240 & 60 & $\mathrm{NA}$ & NA & 600 & 300 \\
\hline 15m (240 layers) & 60 & 15 & 240 & 60 & NA & NA & 300 & 150 \\
\hline
\end{tabular}

\subsection{Model Settings}

Conventionally, stability requirements allow the time step to be changed directly proportional to the horizontal grid size (i.e. if grid size decreases by two, time step decreases by two). However, at fine vertical resolutions, vertical stability often requires a smaller time step. Furthermore, since the sigma coordinates apply very small vertical grid spacings in the region of the embayment, an even smaller time step may be required for the cases utilizing sigma coordinates. The exact time steps used for all simulations can be found in Table 3 .

In order to avoid overly thin partial bottom cells (PBCs), wherever PBCs occur that are less than $10 \%$ full, these bottom cells are removed and the deepest active cell is assigned to be a full cell one level up. Previously cells between 5 and $10 \%$ full were filled to $10 \%$, but this caused striping of tracers in the y-direction, even when visualizing with constant thickness in (3).

MPAS-Ocean includes several parameterizations that were not turned on for this study. This includes the Gent-McWilliams (GM) parameterization for eddy-induced transport (Gent and McWilliams 1990; Gent et al.|1995), Richardson number-based vertical mixing (Pacanowski and Philander 1981), and KPP vertical mixing (Large et al. 1994; Large and Gent|1999). A simple constant vertical viscosity and constant horizontal Laplacian mixing was chosen so that parameters in the study may be set explicitly, and to compare with previous DOME

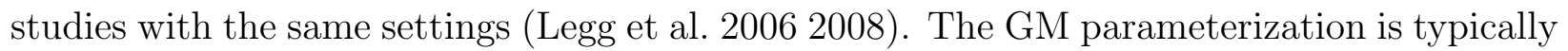
not used in overflow tests, as its purpose is to improve global eddy-induced transports, rather than improving overflow characteristics.

No overflow parameterizations were used in this study. Typically, z-coordinate models have too much mixing in overflows, and isopycnal-coordinate models have too little. Various bottom boundary layer models are used in z-coordinate simulations to eliminate spurious mixing (CAMPIN and Goosse 1999; Beckmann and Döscher 1997; Killworth and Edwards 1999; Song and Chao 2000). Overflow mixing parameterizations are used by isopycnalcoordinate models to increase the entrainment (Legg et al. 2006 2008), for example by the Richardson-number based Ellison and Turner scheme (Ellison and Turner 1959).

\subsection{The Base Case Configuration}

A relatively small parameter space is now explored in order to determine a base case for the full numerical parameter study. The base case is chosen such that the time-averaged metrics match the results in Legg et al. (2008), which investigated the sensitivity of the MITgcm to vertical viscosity, horizontal viscosity, and advection scheme. It was determined that there is insignificant variability due to changes in horizontal viscosity and advection scheme, but that vertical viscosity is important. The recommended choices for these parameters (for the MITgcm) was determined by comparing directly to HIM simulations using the 
Hallberg and Jackson mixing scheme, which is based off of Direct Numerical Simulations and is therefore assumed to be the closest to the "truth". An equivalent comparison is now utilized for setting the vertical and horizontal viscosity parameters to be used in the MPASOcean z-star, z-star with PBC, and sigma simulations. Among the 1D metrics, plume path and plume buoyancy are particularly useful because they show the most variations between cases. Legg et al. (2008) also focused on plume path and plume buoyancy. In general, sigma cases are equally as sensitive as z-star cases to changes in horizontal and vertical viscosity (see Fig. 16).

Based off of the metrics, setting the constant vertical viscosity to $\nu_{\mathrm{v}}=0.05 \mathrm{~m}^{2} \mathrm{~s}^{-1}$ is the best match to HIM for the z-star and z-star PBC vertical coordinate types, and thus, that is the value used for the base case configuration.

A constant harmonic (Laplacian) horizontal viscosity of $5.0 \mathrm{~m}^{2} \mathrm{~s}^{-1}$ is chosen for the base case. As was done in Legg et al. (2008), $0.5 \mathrm{~m}^{2} \mathrm{~s}^{-1}$ and $50 \mathrm{~m}^{2} \mathrm{~s}^{-1}$ are also tested. Overall, the metrics show less sensitivity to horizontal viscosity than vertical viscosity (see Fig. 16), which was also found in Legg et al. (2008). Specifically, the largest horizontal viscosity case has a final plume buoyancy of approximately $68 \%$ the original buoyancy, compared to $58 \%$ from the two smaller horizontal viscosities. Thus, the middle horizontal viscosity value is chosen for the base case, which also matches the base case horizontal viscosity from Legg et al. (2008).

\subsection{Comparison against other models}

Fig. 4 shows a side-by-side comparison of bottom tracer concentration for z-star PBC, sigma, MITgcm, and HIM. The two MPAS-Ocean cases use the base case configuration discussed in the previous section. For the sake of comparison to previous results, the traditional visualization technique of showing the single cell immediately above the topographic slope is utilized. The overall shape and distribution of the plume is very similar in the MPAS-Ocean Z-star and MITgcm results. The plumes are also at approximately the same location along the slope. As seen in Fig. 5, the plume paths of the z-coordinate runs are almost identical, especially for the first $200 \mathrm{~km}$ out of the embayment. The MITgcm model has a final mean buoyancy of about $62 \%$ of its initial value, while the MPAS-Ocean z-coordinate model has a final mean buoyancy of about $57 \%$ of its initial value. This means that the MPASOcean z-coordinate model does appear to have more numerical mixing than the MITgcm model. These small differences could be attributed to different horizontal coordinates (hex vs. quad), different advection schemes, or slightly different time averaging windows. On the other hand, the MPAS-Ocean sigma coordinate results show much less mixing and further across-slope transport than the z-coordinate models when run using the same vertical viscosity, as expected (Ezer and Mellor 2004; Wang et al. 2008).

It was expected that the MPAS-Ocean sigma coordinate results would be more similar to the HIM results than the $\mathrm{z}$-coordinate results, however, the sigma results have much less mixing than the HIM results as well. The results in Fig. 4 and 5 show sigma results run at a smaller vertical viscosity than the z-coordinate results as it provided a better match to the mixing in the HIM simulations. The differences between sigma and HIM are likely due to the mixing parameterizations in the HIM simulations (Legg et al. 2006 2008). There may be additional sensitivity to the slightly different inflow conditions or that the results are from day 40 instead of day 28. 

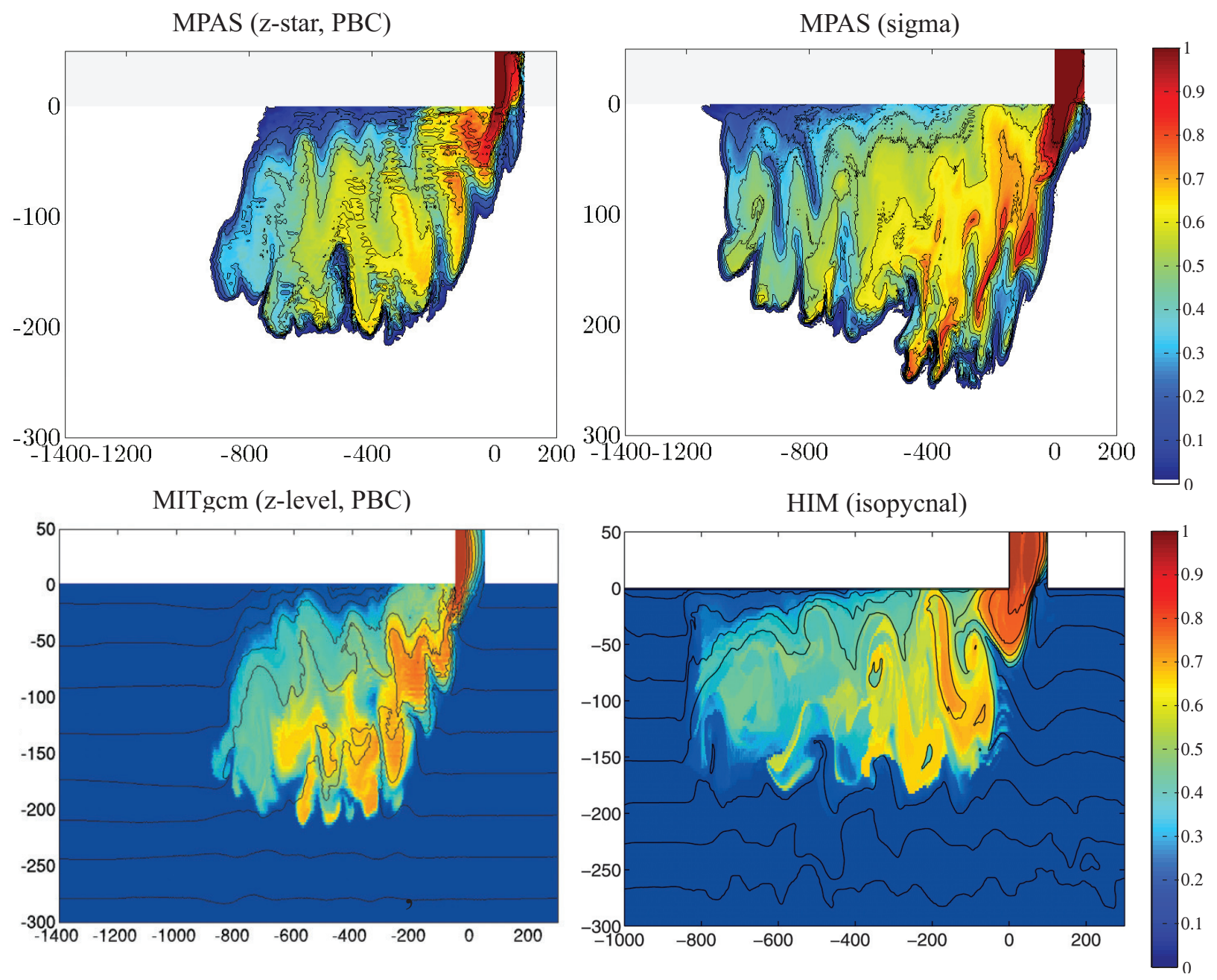

Figure 4: Tracer concentration in the bottom cell for MPAS-Ocean (z-star PBC and sigma), MITgcm (z-level PBC), and HIM (isopycnal). MPAS-Ocean and MITgcm plots are for day 28 and HIM plot is for day 40 (Legg et al. 2008). MPAS-Ocean and MITgcm z-level PBC results are run using base case value $\left(\nu_{\mathrm{v}}=0.05\right.$ $\left.\mathrm{m}^{2} \mathrm{~s}^{-1}\right)$. MPAS-Ocean sigma results are run using $\left(\nu_{\mathrm{v}}=0.005 \mathrm{~m}^{2} \mathrm{~s}^{-1}\right)$. HIM results are run using the Jackson Hallberg mixing scheme (Jackson et al. 2008$)$.

\section{Parameter Study}

The following parameter study is designed as an extension of previous work that looked at the sensitivity of overflows to various numerical parameters (Özgökmen et al. 2004b; Ezer and Mellor 2004; Ezer 2005; Legg et al.|2006; Tseng and Dietrich 2006; Legg et al. 2008; Wang et al. 2008). The following parameters are varied under the control of all other parameters: vertical viscosity, horizontal viscosity, vertical resolution, and horizontal resolution. Special attention is paid to the time step and grid Re in all simulations. Vertical and horizontal viscosity ranges have been chosen based off of the validation studies in Section 4.4. The coarsest horizontal resolution under consideration is $d x=50 \mathrm{~km}$, which is approximately equivalent to a low-resolution, $1^{\circ}$ OGCM grid, such as those used in the IPCC (2013). The resolution of $d x=10 \mathrm{~km}$, is a typical high resolution, $1 / 10^{\circ}$ OGCM grid, and $d x=25 \mathrm{~km}$ was chosen to show the mid-range. The highest resolution simulations use $d x=2.5 \mathrm{~km}$, 


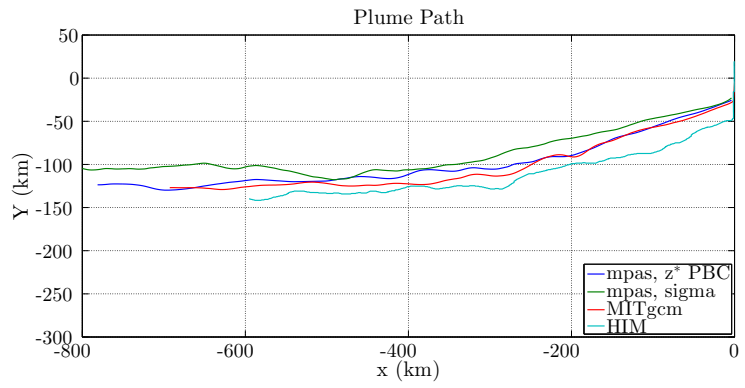

(a)

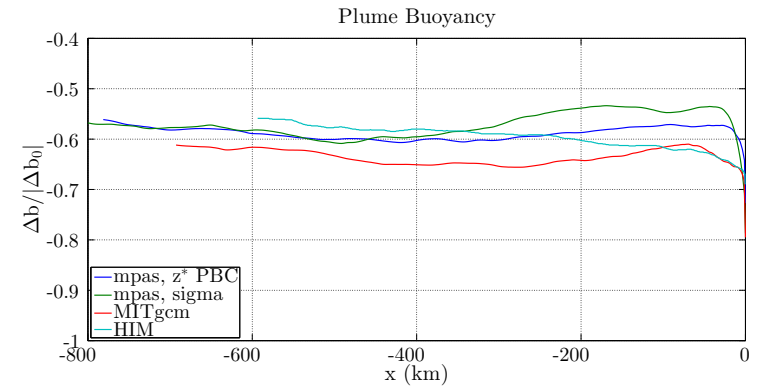

(b)

Figure 5: Plume path and plume buoyancy plots comparing MPAS-Ocean z-coordinate and sigma coordinate simulations with MITgcm and HIM cases. Metrics were time averaged over day 22 to day 40 (for MPASOcean), approximately day 23 to day 37 (for MITgcm), and probably day 0 to day 40 (for HIM). MITgcm and HIM data are from Legg et al. (2008). MPAS-Ocean and MITgcm z-level PBC results are run using base case value $\left(\nu_{\mathrm{v}}=0.05 \mathrm{~m}^{2} \mathrm{~s}^{-1}\right)$. MPAS-Ocean sigma results are run using $\left(\nu_{\mathrm{v}}=0.005 \mathrm{~m}^{2} \mathrm{~s}^{-1}\right)$. HIM results are run using the Jackson Hallberg mixing scheme (Jackson et al. 2008).

which has currently only been applied in regional models and not yet applicable to OGCMs. The exact numbers are chosen to match resolutions used in other idealized overflow studies (Legg et al. 2006 2008; Wang et al.|2008). Similarly, the vertical resolution range used for this study matches other models (Legg et al. 2006 2008; Wang et al. 2008). The simulations use vertical resolutions of $d z=120 \mathrm{~m}$ (30 layers), $d z=60 \mathrm{~m}$ (60 layers), $d z=30 \mathrm{~m}$ (120 layers), and $d z=15 \mathrm{~m}$ (240 layers). DOME was designed to mimic the configuration of the Nordic Sea overflows, which have sill depths around 500-800 m and final product water reaching neutral buoyancy around 1600-3000 $\mathrm{m}$ deep (Legg et al. 2009). The range of vertical resolution parameters provides a reasonable variety of vertical representations of these overflow structures. Global ocean models have layers ranging from 30 to $150 \mathrm{~m}$ in thickness at sill depths and 100-250 $\mathrm{m}$ at product water depths (Maltrud and McClean 2005; Ringler et al. 2013), but ocean models planned for the near future will have much finer vertical grids.

Table 4 summarizes the parameter ranges used in this study. All combinations of vertical and horizontal resolutions were tested. These combinations were tested with a variety of horizontal and vertical viscosities, resulting in over 300 different cases. The choices were made such that the sensitivity to each individual parameter could be understood (e.g. changing vertical resolution, horizontal resolution, vertical viscosity, or horizontal viscosity independently), as well as the sensitivity to the grid Reynolds number, which characterizes the strength of the turbulence in the system in relation to the grid scale. When the grid Reynolds number is sufficiently high, spurious mixing occurs as the numerical discretization fails to effectively resolve the turbulence. For harmonic diffusion, the horizontal and vertical grid Reynolds numbers are defined as

$$
R e_{d x}=\frac{U d x}{\nu_{h}}
$$

$$
R e_{d z}=\frac{W d z}{\nu_{v}}
$$


Table 4: MPAS-Ocean model parameters used for this study. Bold indicates base case, where different vertical viscosities are used for z-star PBC and sigma base cases. Most, but not all, combinations of resolutions and viscosities were conducted.

\begin{tabular}{r|l}
\hline Horizontal resolution, $\mathrm{km}$ & $\mathbf{2 . 5}, 10,25,50$ \\
\hline Vertical resolution, $\mathrm{m}$ & $15,30, \mathbf{6 0}, 120$ \\
\hline Horizontal viscosity, $\mathrm{m}^{2} \mathrm{~s}^{-1}$ & $0.5, \mathbf{5}, 20,50,100$ \\
\hline Vertical viscosity: & \\
\hline wide range, $\mathrm{m}^{2} \mathrm{~s}^{-1}$ & $0.002,0.005,0.01,0.025,0.05,0.5$ \\
\hline narrow range for z-star PBC, $\mathrm{m}^{2} \mathrm{~s}^{-1}$ & $0.0125,0.025, \mathbf{0 . 0 5}, 0.1$ \\
\hline narrow range for sigma, $\mathrm{m}^{2} \mathrm{~s}^{-1}$ & $0.00125,0.0025, \mathbf{0 . 0 0 5}, 0.01$ \\
\hline Grid types & z-level PBC, z-star full cell, z-star PBC, sigma \\
\hline
\end{tabular}

where the horizontal and vertical velocity scales for all cases, $U$ and $W$, are computed from the plume location of the base case after 40 days. For the base case, $R e_{d x}=150$ and ranges from 15 to $3 \times 10^{4}$ across all cases, while in the vertical, $R e_{d z}=0.9$ for the base case and ranges from 0.1 to 6.7 across all cases. Ilicak et al. (2012) found that spurious mixing is strongly dependent on the horizontal grid Reynolds number. They tested idealized cases from $R e_{d x}=1.5-1.5 \times 10^{5}$, and showed that spurious dianeutral transport is significantly reduced when $R e_{d x}<10$. Our ranges for resolution and viscosity were based on past DOME configurations and typical real-world settings, which have a similar but smaller range of $R e_{d x}$.

\subsection{Sensitivity to Vertical Parameters}

In this section, the simulations' sensitivity to individual vertical parameters (vertical resolution and vertical viscosity) will be explored, as well as the sensitivity to changing the two simultaneously such that the vertical grid Reynolds number is held constant. The effects of vertical and horizontal viscosity are strongest in regions of large vertical and horizontal gradients of velocity, respectively, with the largest shear effects occurring in the bottom Ekman layer. However, the system's response to changes in vertical viscosity should be qualitatively similar to that for horizontal viscosity. Both are responsible for smoothing the divergence of horizontal velocity, which leads to a reduction in grid scale random fluctuations of both horizontal and vertical velocity (Ilicak et al. 2012). Thus, increasing either horizontal or vertical viscosity (or decreasing grid Reynolds number) acts to reduce spurious mixing, resulting in a more laminar flow with less entrainment. Since the largest shear occurs near the bottom boundary where vertical gradients of velocity are large, vertical viscosity affects the plume dynamics more than the horizontal viscosity.

Fig. 6] shows a tiled plot of 16 different cases for two different metrics. All cases are run using z-star PBC with a horizontal resolution of $2.5 \mathrm{~km}$. The top 16 plots show bottom tracer concentration with a constant visualization thickness, $\Delta z_{\text {plot }}=120 \mathrm{~m}$, across all resolutions. The bottom 16 plots show plume thickness. Each column represents a different vertical viscosity with the largest on the far left, $\nu_{v}=0.1 \mathrm{~m}^{2} \mathrm{~s}^{-1}$, and the smallest on the far right, $\nu_{v}=0.0125 \mathrm{~m}^{2} \mathrm{~s}^{-1}$. Vertical resolution is varied along the rows where the top row is the coarsest resolution, $d z=120 \mathrm{~m}$, and the bottom row is the finest resolution, $d z=15 \mathrm{~m}$. Due to the specific parameter values used, the upper-left to lower-right diagonals of the tiled visualizations show cases with constant vertical grid Reynolds numbers. The overall plume shape and how the tracer concentration is distributed within the plume as vertical viscosity 
and vertical resolution change can be observed by looking at the first 16 plots of Fig. 6. The change in eddying behavior can be observed in the plume thickness plots in the last 16 plots of Fig. 6. An overall qualitative look at these plots shows that decreasing vertical viscosity results in the plume to propagating further along-slope. Finer vertical resolutions transport higher concentrations of the plume further downslope. At finer vertical resolutions there is higher sensitivity to variations in vertical viscosity.

Legg et al. (2006) found that increasing vertical viscosity led to a suppression of eddy activity using the HIM model. The same finding was also reported in Ezer and Mellor (2004). The results presented in Fig. 6 agree with the previous findings, but only for eddies in the eastern extents of the plume, near the embayment. When the eddies near the embayment are suppressed, the plume levels off and moves along slope rather than downslope, which has also been observed in Legg et al. (2008). A reversal of this behavior is observed in the region near the plume front, where increased vertical viscosity leads to stronger eddies that have partially traveled downslope. Eddy strength also increases as vertical resolution coarsens, especially for cases run at the smallest vertical viscosity. It is clear that the plume behavior, particularly the eddy behavior, is dependent on both vertical viscosity and vertical resolution, and that the two effects are interrelated. A more quantitative discussion of these results are given in the following sections.

We begin with an overview of how to interpret the 1D metrics, and proceed to their sensitivity to vertical parameters. The plume path (Fig. 7a) shows the average path of the plume as it descends the slope. Since the plume is on a decreasing slope, the $Y$ location on the y-axis indicates how far down the slope the plume has descended in addition to its southward extent. If there is more mixing, the plume will not descend as far and will level off at a higher $Y$ value. The plume buoyancy (Fig. $7 \mathrm{~b}$ ) is scaled by the initial buoyancy, so that value on the $\mathrm{y}$-axis is the percentage of the initial buoyancy. Plume buoyancy is initially -1 at the inlet of the embayment, and adjusts to values near -0.7 with little mixing (equivalent to saying the plume is approximately $70 \%$ its initial buoyancy), and -0.4 (40\% its initial buoyancy) with high mixing. Mean plume height and mean plume thickness (Fig. $7 \mathrm{c}$ and $7 \mathrm{~d}$ ) give insight on the vertical structure of the plume. Whereas the mean plume height continues to increase as the plume descends down the slope, the mean plume thickness shows that total thickness of the plume peaks in the middle of the plume where there is the highest eddy activity. The westward transport (Fig. 7e) increases until $x=-600 \mathrm{~km}$ and then decreases. The dominant term in the entrainment coefficient definition (Equation 9 ) is $d T / d x$, so entrainment is large and positive just after the embayment until $x=-150 \mathrm{~km}$, small to $x=-650 \mathrm{~km}$, and then negative for the remaining part of the domain.

\subsubsection{Sensitivity at Coarse Vertical Resolution}

At the coarsest resolution of $d z=120 \mathrm{~m}$, plume, path, transport, and entrainment are less sensitive to vertical viscosity than at finer vertical resolutions. For the case with the lowest vertical viscosity, the plume buoyancy in Fig. $7 \mathrm{~b}$ levels off at $45 \%$ of its initial buoyancy, compared to $55 \%$ for high vertical viscosity. Low vertical viscosity allows more turbulence, which causes more mixing and entrainment, so that product water is lighter, as summarized at the top of Fig. 9. Lower vertical viscosity does result in an increase in plume height as can be seen in Fig. [7c, due to the dilution of the plume in the vertical. Since plume thickness and plume height are indications of eddying behavior, at course vertical resolution, a lower 

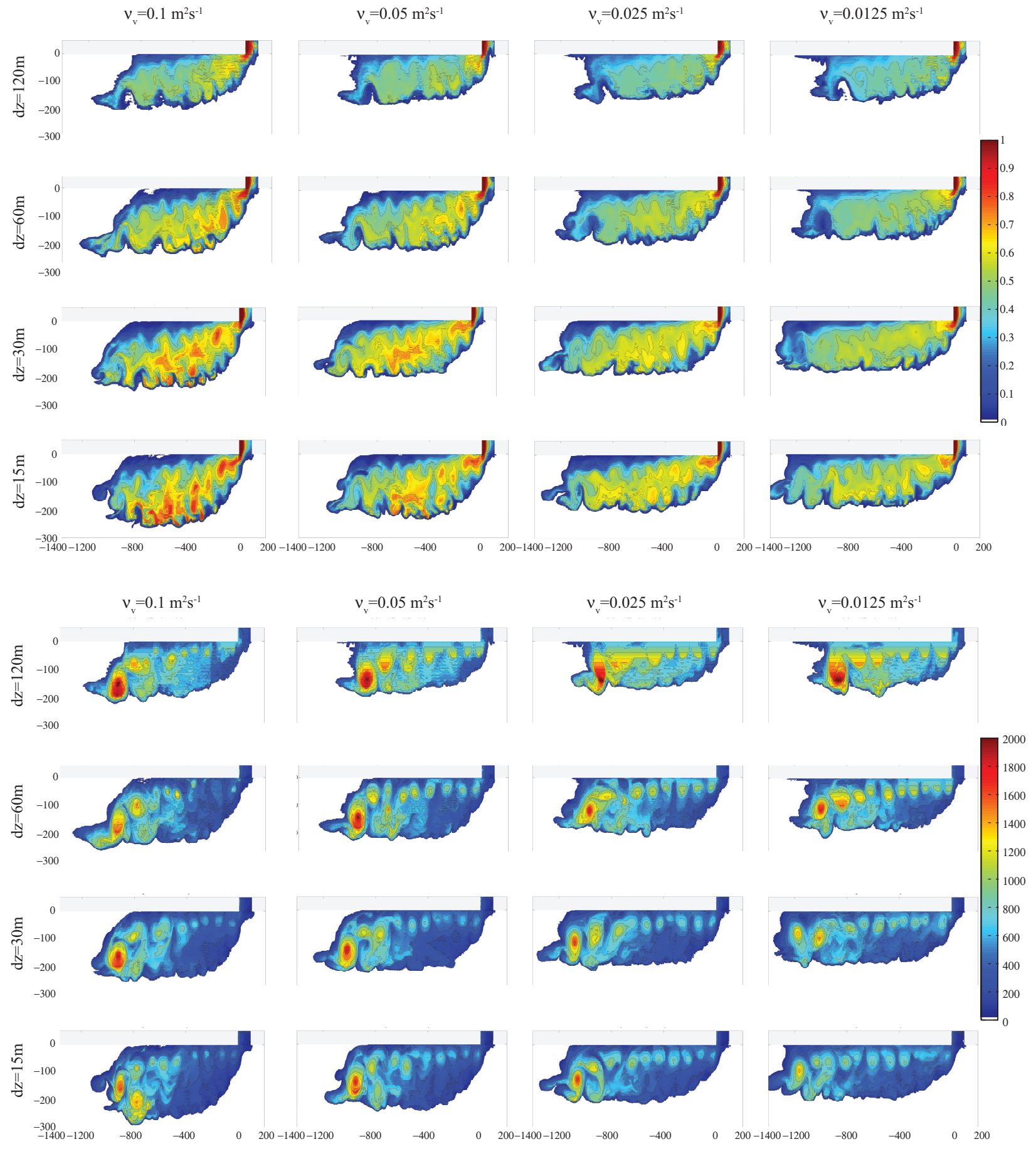

Figure 6: Top 16 plots are bottom tracer concentration with $\Delta z_{p l o t}=120 \mathrm{~m}$, for the $2.5 \mathrm{~km}$ resolution study, with z-star PBC. Bottom 16 plots are plume thickness for the same cases. All are plotted at day 40.

vertical viscosity results in more intense eddies, which matches what was found in Ezer and Mellor (2004); Tseng and Dietrich (2006); Legg et al. (2006). The plume thickness and height do not show the same pattern west of approximately $x=-640 \mathrm{~km}$. This is likely due to the strong eddy in that region, which appears as a filament that is partially separated from the 


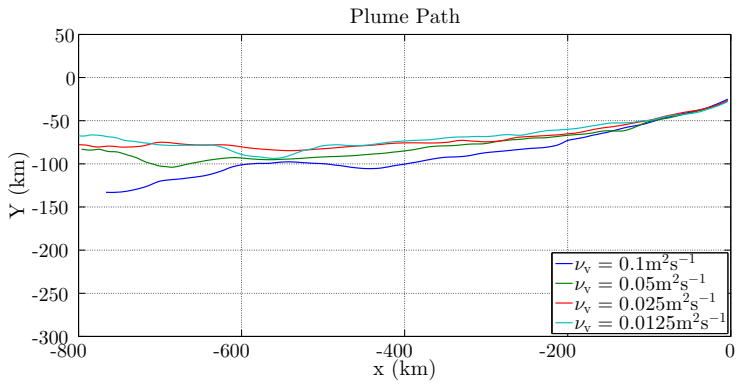

(a)

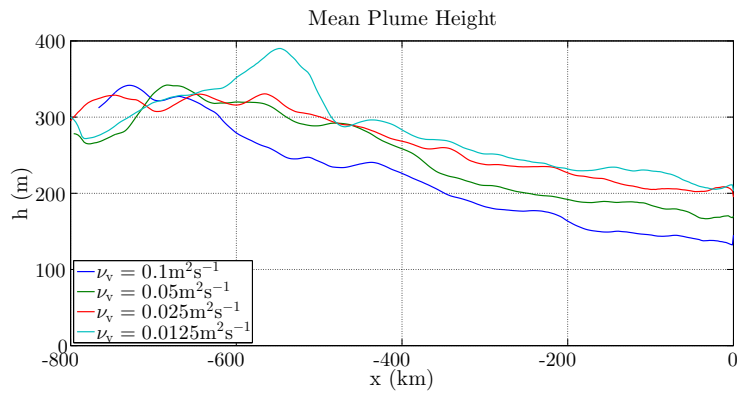

(c)

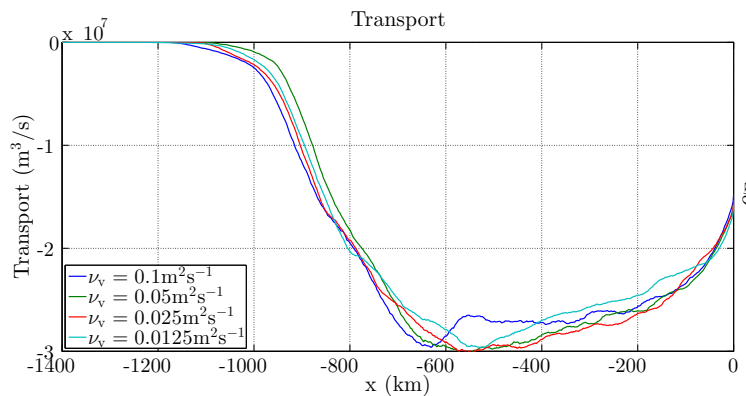

(e)

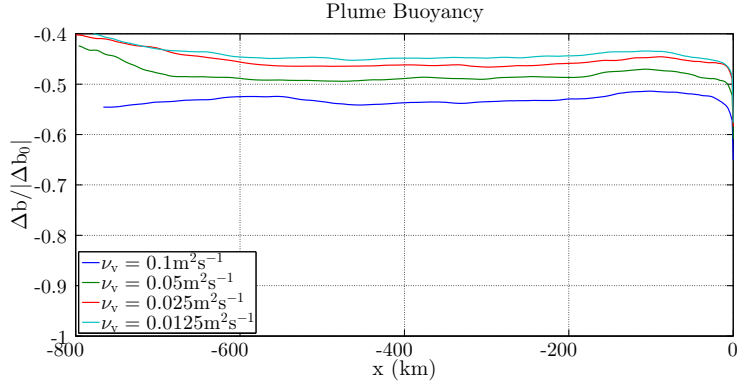

(b)

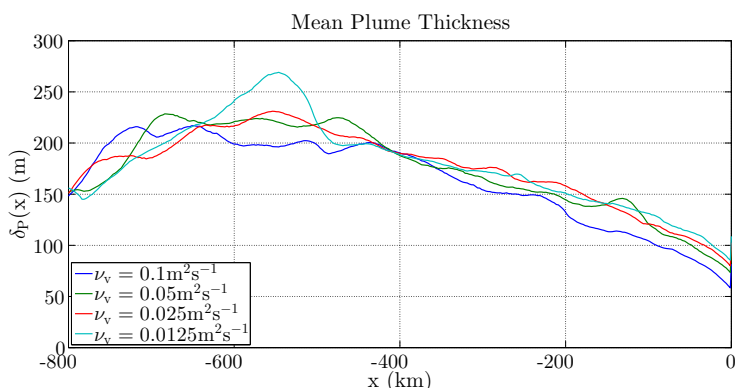

(d)

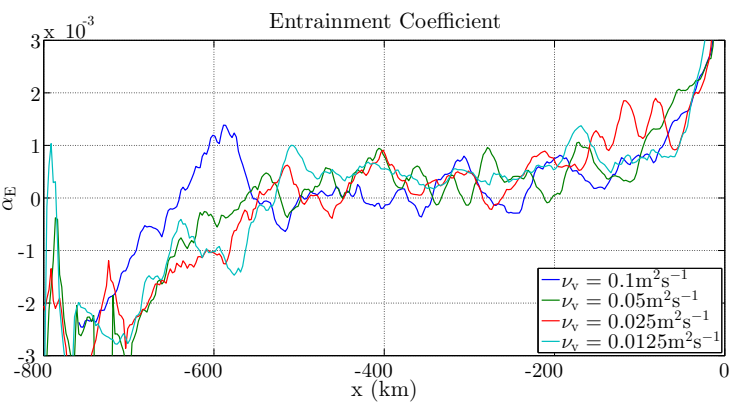

(f)

Figure 7: Plume path, plume buoyancy, mean plume height, mean plume thickness, transport, and entrainment coefficient for $d x=2.5 \mathrm{~km}$ horizontal resolution with z-star PBCs and a constant $d z=120 \mathrm{~m}$ for all four vertical viscosities. Metrics are time-averaged over the period of day 22 to day 40. 


\subsubsection{Sensitivity at Fine Vertical Resolution}

Sensitivity to vertical viscosity at high versus low resolutions is quite different. To illustrate, Fig. 8 shows the same 1D metrics and comparisons as Fig. 7 but for a constant vertical resolution of $d z=15 \mathrm{~m}$. The plots indicate that if the resolution is not high enough, the simulation does not capture the additional dynamics afforded by varying the viscosity. For these high vertical resolution simulations, as vertical viscosity increases, the plume path gradually steepens (Fig. 8a) and the plume buoyancy decreases (Fig. 8b). In the region near the front of the plume, mean plume height (Fig. 8c) and mean plume thickness (Fig. 8d) increase as vertical viscosity increases. In a localized region close to the embayment (between $x=0$ and $-50 \mathrm{~km}$ ), there is a slight increase in transport (Fig. 8e) and an associated decrease in entrainment coefficient (flux into the plume) (Fig. 8f) for larger values of vertical viscosity. The small differences in entrainment of ambient water early on are enough to alter the plume buoyancy, which then remains nearly constant as it propagates across the slope. 


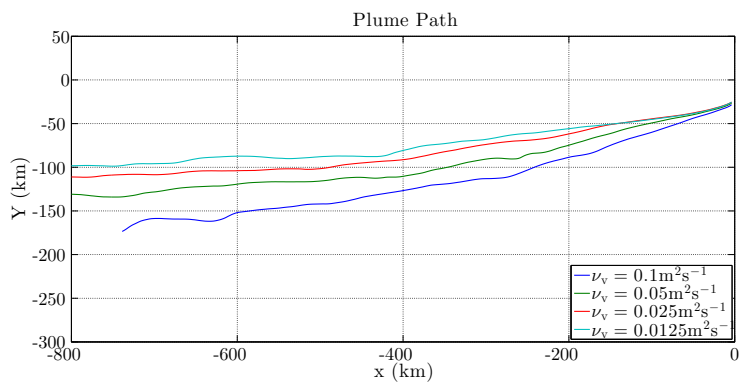

(a)

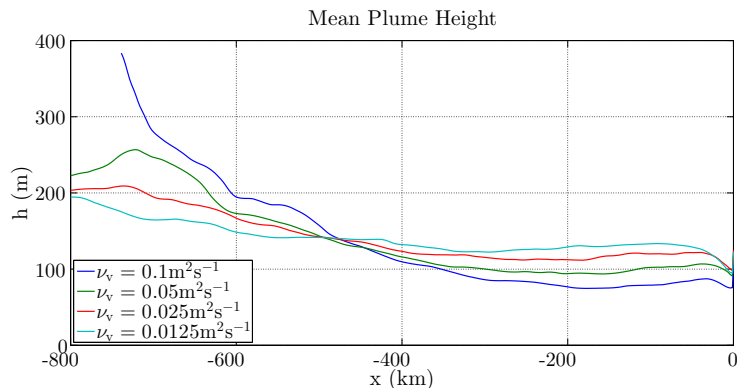

(c)

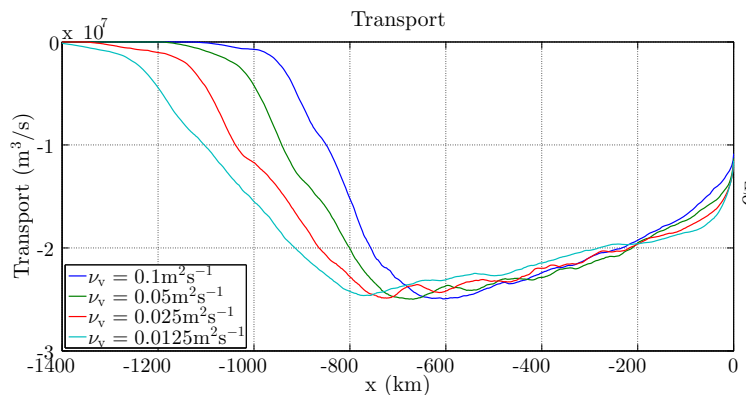

(e)

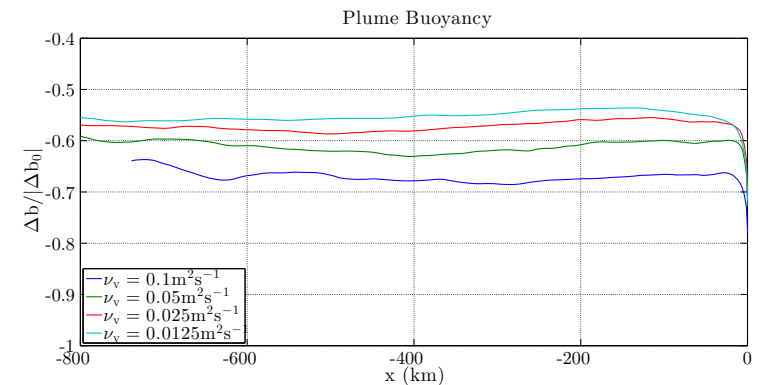

(b)

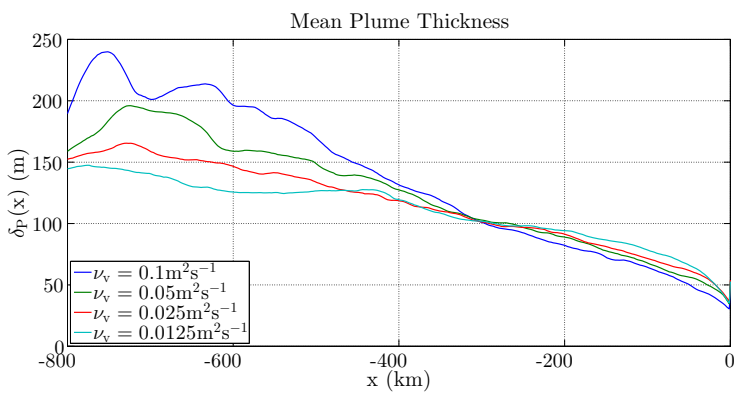

(d)

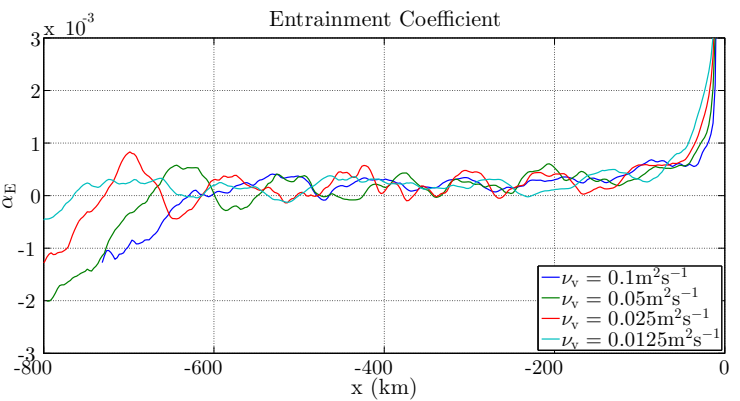

(f)

Figure 8: Plume path, plume buoyancy, mean plume height, mean plume thickness, transport, and entrainment coefficient for $d x=2.5 \mathrm{~km}$ horizontal resolution with z-star PBCs and a constant $d z=15 \mathrm{~m}$ for all four vertical viscosities. Metrics are time-averaged over the period of day 22 to day 40. 


\subsubsection{Comparing Sensitivity at Fine and Coarse Vertical Resolutions}

As was mentioned in the coarse vertical resolution discussion, the effect of vertical viscosity reverses trends inside the plume. For all vertical resolutions, the plume descends further along slope as vertical viscosity decreases. This makes the plume thickness comparison in the region near the front of the plume irrelevant. This area is cut off in most of the plots of plume thickness. In the western region of the plume, as vertical viscosity increases, the plume thickens and eddy strength increases. In the eastern region of the plume, the trend reverses: as vertical viscosity decreases, eddy strength increases. For each vertical resolution, there is an $\mathrm{x}$ location where the trend reverses. For $d z=120 \mathrm{~m}$, the trend reverses at $x=-640 \mathrm{~km}$. For $d z=60 \mathrm{~m}$, the trend reverses at $x=-470 \mathrm{~km}$. For $d z=30 \mathrm{~m}$, the trend reverses at $x=-430 \mathrm{~km}$. For $d z=15 \mathrm{~m}$, the trend reverses at $x=-300 \mathrm{~km}$. The eastern region matches what was found in Legg et al. (2008). Lower vertical viscosity results in stronger eddies and more numerical mixing in the region close to the embayment, that is the eastern region of the plume. This results in less dense plumes that descend less down the slope, which keeps the eddies localized near the top of the slope. With higher vertical viscosity, the eddies in the eastern region are suppressed, thus lowering numerical mixing. This results in a denser plume that descends down the slope more, which likely provides additional kinetic energy to the plume, thus strengthening the downslope eddies in the western region. The dynamics of the different eddying regimes will be the focus of a future study by the authors.

\subsubsection{Summary of Vertical Parameter Sensitivity for all Cases}

The intricate relationships between vertical parameters can be further understood by looking at scalar metrics, which are averaged from the 1D metrics and can be used to characterize the plume dynamics of a single simulation in a straightforward manner. For these 0D comparisons, the focus is on initial angle of descent and mean final buoyancy, described in Sec. 3.3. Initial angle of descent provides a bulk value for the steepness of the plume's descent downslope. Mean final buoyancy characterizes the density and depth of the plume after the initial adjustment. As can be seen in 1D plots, plume buoyancy levels off fairly quickly after the exit from the embayment.

Fig. 9 shows both of the scalar metrics for the entire parameter study for z-star PBC. For all the horizontal resolutions, initial angle of descent is slightly sensitive to vertical resolution, especially at high horizontal resolution and small vertical viscosity. The largest percent difference in initial angle of descent is for the finest horizontal resolution cases and the two largest vertical viscosities, which has a maximum of $30 \%$ change between different vertical resolutions. The two smaller viscosities at the finest horizontal resolution have about a $15 \%$ change in initial angle of descent values. The sensitivity is similar for the largest vertical viscosity cases run at the intermediate horizontal resolution. However, all other cases show almost not change in initial angle of descent values versus vertical resolution. On the other hand, initial angle of descent does show some sensitivity to vertical viscosity for all resolutions. At $d x=2.5 \mathrm{~km}$ horizontal resolution, initial angle of descent in Fig. 9a is very sensitive to vertical viscosity, with percent differences as high as almost $50 \%$ for the $d z=60 \mathrm{~m}$ cases. Legg et al. (2006) also found that initial angle of descent was relatively insensitive to changes in resolution, even when both horizontal and vertical resolutions were changed simultaneously. However, Legg et al. (2008) then showed that initial angle of descent is sensitive to vertical viscosity. On the other hand, mean final buoyancy shows strong 
sensitivity to both vertical viscosity and vertical resolution. The percent differences are as high as about $20 \%$ for changes in vertical resolution and about $23 \%$ for changes in vertical viscosity at the finest horizontal resolution. These percent differences decrease as horizontal resolution decreases. At the intermediate resolution, the percent difference in mean plume buoyancy for changes in vertical viscosity are about $16 \%$, and for changes in vertical resolution, they are about $11 \%$. At the lowest resolution, they are insignificantly different. In general, as either vertical resolution decreases or vertical viscosity decreases, the final mean plume density decreases, which matches the findings of Riemenschneider and Legg (2007). Also, in Legg et al. (2006), it was shown that as vertical resolution was coarsened from $d z=30 \mathrm{~m}$ to $d z=144 \mathrm{~m}$, the final buoyancy of the overflow decreased. Since the horizontal and vertical resolutions were varied simultaneously in those comparisons, it is not evident which has a greater effect on the final buoyancy. However, this work shows that it is likely the changes in vertical resolution, not the changes in horizontal resolution.

Vertical viscosity is a slightly stronger control on mean final buoyancy and is less computationally expensive than increasing vertical resolution. Therefore, going to resolutions finer than $d z=60 \mathrm{~m}$ does not seem worthwhile for these types of overflows, because viscosity may be decreased to reduce mixing instead. This is particularly true for $d x=10 \mathrm{~km}$, where mean final buoyancy is not changed by moving to vertical resolutions finer than $d z=60 \mathrm{~m}$. This is consistent with the findings of Winton et al. (1998), which suggests that z-coordinate models need to be run with several points in the frictional boundary layer to match the results given by density coordinate models and theory. This would mean for an overflow plume of approximately $160 \mathrm{~m}$ in thickness, the vertical resolution should be approximately $32 \mathrm{~m}$. These two recommendations approximately agree.

The results in Fig. 9 may be interpreted using the grid Reynolds number, as summarized by the diagrams at the top. For example, in Fig. 9b, mean final buoyancy increases with higher $d z$ and larger vertical viscosity. The highest value of vertical grid Reynolds number $\left(R e_{d z}=6.7\right.$, when $d z=120 \mathrm{~m}$ and $\left.\nu_{v}=0.0125 \mathrm{~m}^{2} \mathrm{~s}^{-1}\right)$ produces the most mixing and highest final buoyancy, while the lowest value $\left(R e_{d z}=0.1\right.$, from $d z=15 \mathrm{~m}$ and $\left.\nu_{v}=0.1 \mathrm{~m}^{2} \mathrm{~s}^{-1}\right)$ produces the least. Despite this pattern, $R e_{d z}$ is not strictly a controlling parameter for these results. Gray circles indicate constant $R e_{d z}$ values within each panel, and produce varying values for initial angle of descent and mean final buoyancy. 


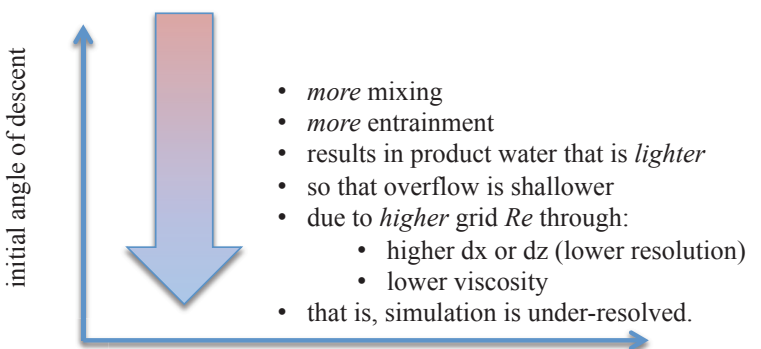

free parameter

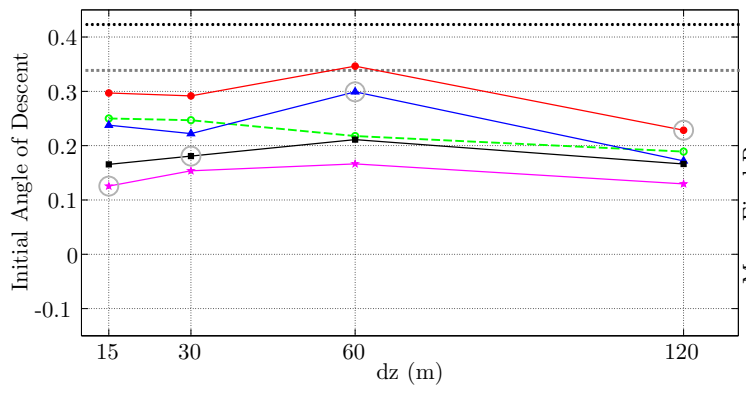

(a) $d x=2.5 \mathrm{~km}$

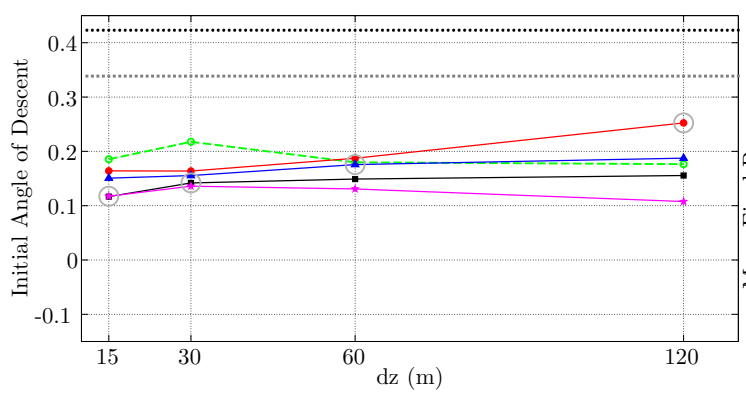

(c) $d x=10 \mathrm{~km}$

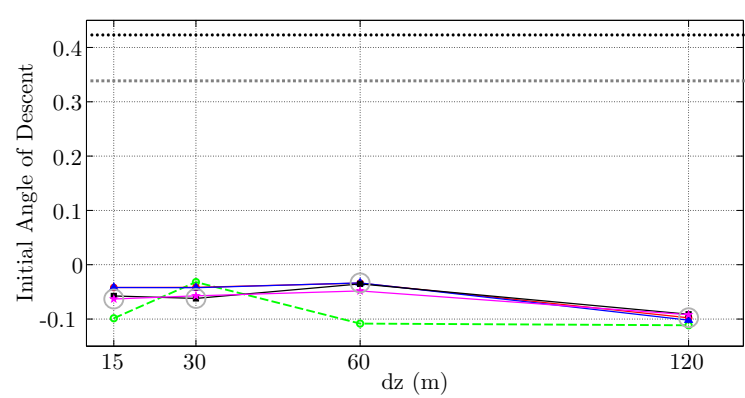

(e) $d x=50 \mathrm{~km}$

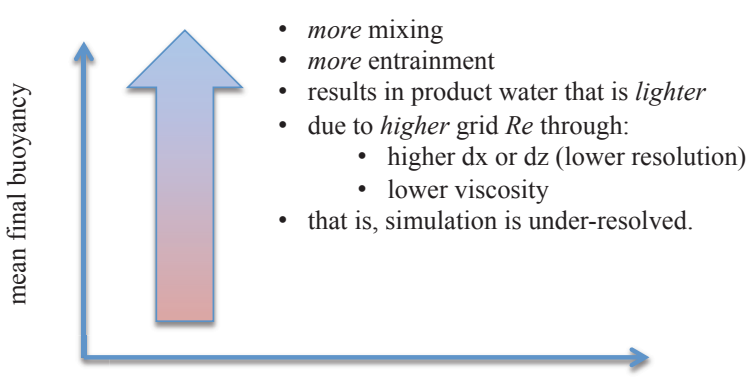

free parameter

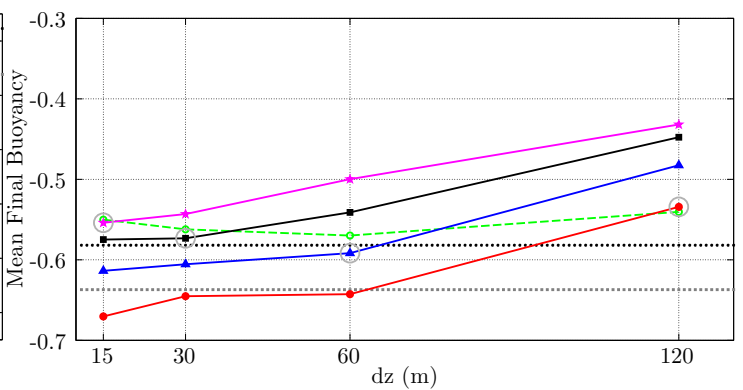

(b) $d x=2.5 \mathrm{~km}$

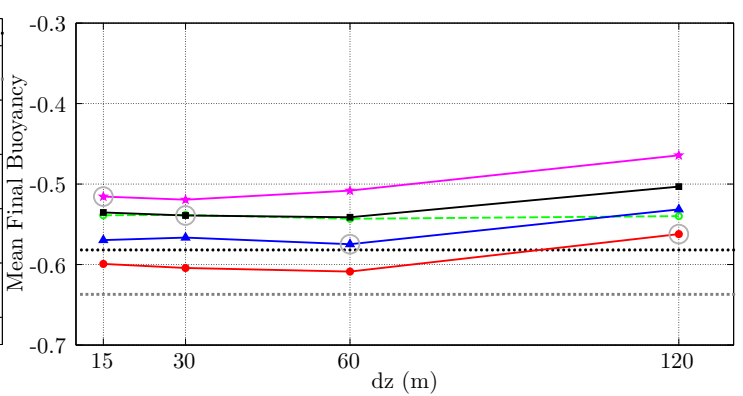

(d) $d x=10 \mathrm{~km}$

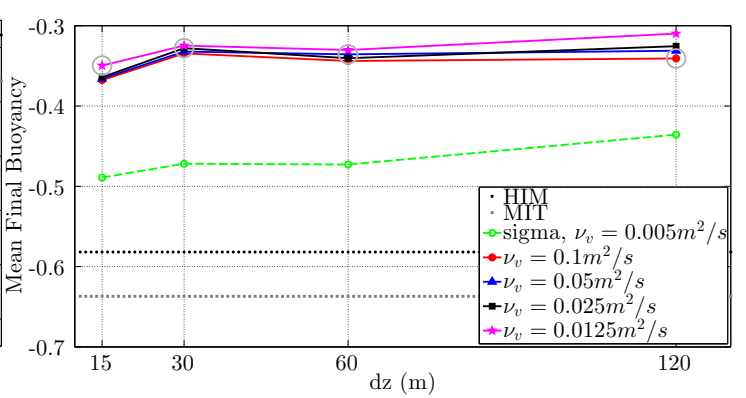

(f) $d x=50 \mathrm{~km}$

Figure 9: Averaged scalar metrics, showing initial angle of descent (left column) and mean final buoyancy (right column) for three horizontal resolutions (rows). All solid lines are MPAS-Ocean z-star PBC, with varying vertical viscosities labelled in the legends. Dashed green lines are MPAS-Ocean using sigma vertical coordinates and $\nu_{v}=0.005 \mathrm{~m}^{2} / \mathrm{s}$. Dotted lines are the reference cases for the MITgcm (black) and HIM models (gray). MITgcm used $d x=2.5 \mathrm{~km}, d z=60 \mathrm{~m}$, and $\nu_{v}=0.05 \mathrm{~m}^{2} / \mathrm{s}$. HIM used $d x=2.5 \mathrm{~km}, 25$ isopycnal layers, and $\nu_{v}=10^{-4} \mathrm{~m}^{2} / \mathrm{s}$. Gray circles indicate the MPAS-OCEAN cases that have a constant vertical grid Reynolds number $\left(R e_{d z}=0.9\right)$. The legend in (f) applies for all six plots. 


\subsection{Sensitivity to Horizontal Parameters}

In this section, the simulations' sensitivity to individual horizontal parameters (horizontal resolution and horizontal viscosity) will be explored, as well as the sensitivity to changing the two simultaneously such that the horizontal grid Reynolds number is held constant. First, a tour of the results will be explained.

Fig. 10 shows bottom tracer concentration plotted at a visualization thickness of $\Delta z_{\text {plot }}=$ $120 \mathrm{~m}$. Each column represents a different horizontal resolution and viscosity, and each row represents a different vertical resolution and viscosity. These parameters were chosen such that the horizontal grid Reynolds number $\left(R e_{d x}=150\right)$ and vertical grid Reynolds number $\left(R e_{d z}=0.9\right)$ were constant. Fig. 11 shows the same orientation of tiled plots but for plume thickness. As with Legg et al. (2006), the $d x=2.5 \mathrm{~km}$ resolution case has eddies present, which can be seen in the plots of plume thickness in Fig. 6. Legg et al. (2006) also found that at $10 \mathrm{~km}$ resolution, eddies are no longer present and the plume looks similar to the laminar regime found at higher Ekman numbers in Cenedese et al. (2004). The MPASOcean simulations confirm this when run at approximately the same vertical resolution as the MITgcm simulations (which was run at $d z=144 \mathrm{~m}$ ). However, with the higher vertical resolution of $d z=15 \mathrm{~m}$, eddies are present at the horizontal resolution of $d x=10 \mathrm{~km}$. In fact, eddies are present at a vertical resolution of $d z=60 \mathrm{~m}$, which is shown in Fig. 11. As was found in Legg et al. (2006), the plume structure is not properly resolved in the lowest horizontal resolution of $d x=50 \mathrm{~km}$. This does not improve as vertical resolution is increased, or by varying horizontal and vertical viscosity. It appears that there is a qualitative shift in the plume evolution between 10 and $50 \mathrm{~km}$ horizontal resolution, that is unaffected by the viscosity parameters and vertical resolution. The cause of this shift is discussed below. Lastly, an interesting difference between horizontal and vertical resolution can be observed in Fig. 10. As vertical resolution increases, the plume propagates further along the slope (in $x$ ). However, as horizontal resolution increases, the plume extent is less far along the slope (in $x$ ). This is particularly evident at higher vertical resolutions and also occurs in sigma vertical coordinate simulations. 

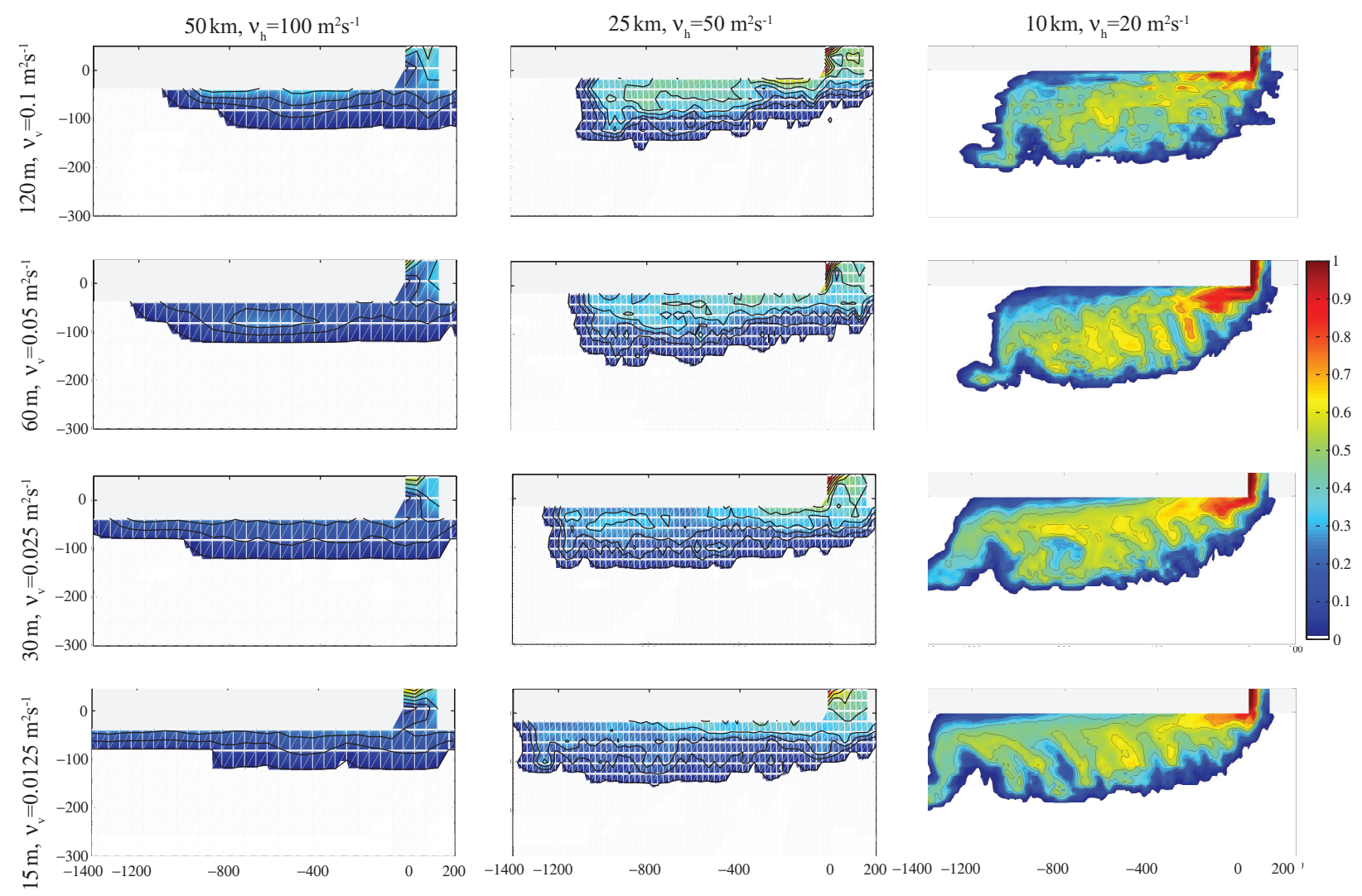

Figure 10: Bottom tracer concentration for z-star PBC with $\Delta z_{p l o t}=120 \mathrm{~m}$ for all 3 horizontal resolutions and 4 vertical resolutions with a constant horizontal $\left(R e_{d x}=150\right)$ and vertical grid Reynolds number $\left(R e_{d z}=0.9\right)$. All plots are at day 40. The corresponding plots for $d x=2.5 \mathrm{~km}$ appear in along the diagonal of Fig. 6, top plots. 

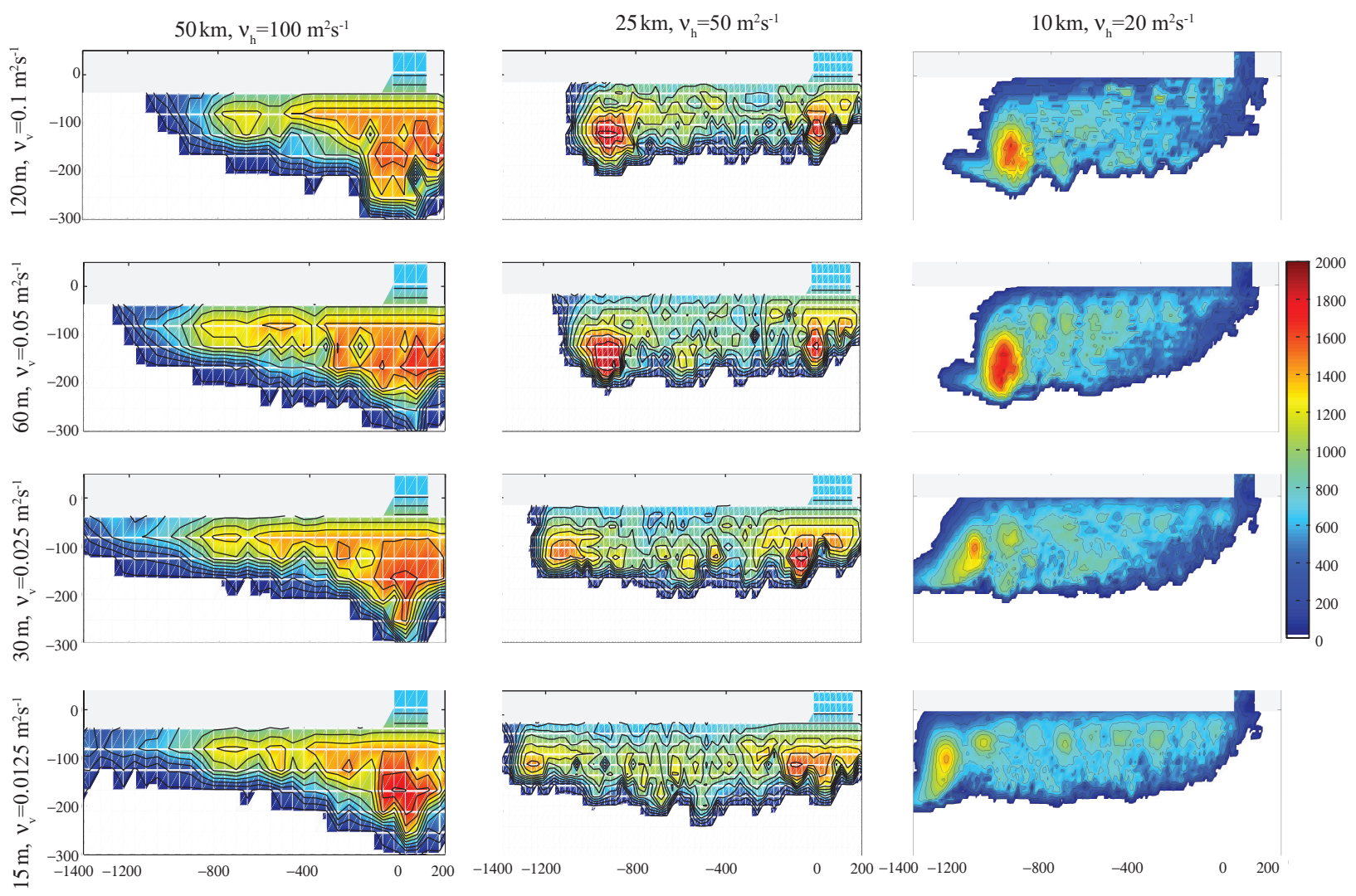

Figure 11: Plume thickness for z-star PBC for all 3 horizontal resolutions and 4 vertical resolutions with a constant horizontal $\left(R e_{d x}=150\right)$ and vertical grid Reynolds number $\left(R e_{d z}=0.9\right)$. All plots are at day 40 . The corresponding plots for $d x=2.5 \mathrm{~km}$ appear in along the diagonal of Fig. 6, top plots. 
Fig. 12 shows all 1D metrics for four horizontal resolutions, with all other parameters held constant $\left(d z=60 \mathrm{~m}, \mathrm{z}\right.$-star PBC vertical coordinate, $\nu_{v}=0.5 \mathrm{~m}^{2} / \mathrm{s}$, and $\left.\nu_{h}=5 \mathrm{~m}^{2} / \mathrm{s}\right)$. As can be inferred from the $2 \mathrm{D}$ plots, the $d x=50 \mathrm{~km}$ resolution case produces significantly different plume dynamics. These low resolution simulations are so under-resolved in the horizontal, that varying any other parameter makes no difference. These under-resolved simulations produce results that are much different for nearly all of the metrics when compared to the higher horizontal resolution simulations. For example, there is over a $40 \%$ difference in final plume buoyancy values. The max mean plume height is over $700 \mathrm{~m}$ more in the low resolution cases versus the highest resolution case. This can also be seen in Fig. 9. The $d x=2.5 \mathrm{~km}$ and $d x=10 \mathrm{~km}$ horizontal resolution scalar metrics are quite similar, while $d x=25 \mathrm{~km}$ is between the $d x=10 \mathrm{~km}$ and $50 \mathrm{~km}$ in most metrics.

The primary reason for the poor performance of the $50 \mathrm{~km}$ grid is that it does not sufficiently resolve the Rossby Radius of deformation, which is $20-50 \mathrm{~km}$ in this idealized domain (Wang et al. 2008; Legg et al. 2008). Simulations are generally considered "eddypermitting" if they contain at least two grid cells per eddy radius. Visually, eddies have a 50 $\mathrm{km}$ radius (Fig. 11), roughly corresponding to the Rossby Radius, so the $d x=25 \mathrm{~km}$ resolution lies in the transition between non-eddy-permitting $(d x=50 \mathrm{~km})$ and eddy-permitting $(d x=10 \mathrm{~km})$.

The metrics and plots show that at $d x=50 \mathrm{~km}$, a great deal of mixing occurs within the embayment. Similar behavior can be seen in (Legg et al. 2008, Fig 13c), where the MITgcm used $d x=50 \mathrm{~km}$. In this idealized DOME domain, the embayment is analogous to the end of the channel in realistic overflows. In a low-resolution z-coordinate global ocean model, mixing would occur in the channel, even before the plume exits and descends. This can be seen, for example, in Fig 11 of Chang et al. (2009), where there is very little heavy water at the Faroe Bank Channel exit in the 1 degree and 1/3 degree simulations; and in Fig. 13b of Riemenschneider and Legg (2007), where a resolution of $d x=50 \mathrm{~km}$ produces much lower density than higher resolution cases before the channel exit.

A doubling of horizontal resolution typically increases computation time by a factor of 8-10: doubling in two horizontal directions, a halving of the timestep, plus imperfect scaling. Thus it is important to assess what grid cell size is required to properly resolve overflows. All results of this study show that $d x=50 \mathrm{~km}$ is insufficient without the application of eddy parameterizations or overflow parameterizations, while $d x=10 \mathrm{~km}$ is sufficient, and increasing to $d x=2.5 \mathrm{~km}$ provides no further gains. The $d x=25 \mathrm{~km}$ case is in the transition region between having sufficient and insufficient resolution.

Riemenschneider and Legg (2007) show that simulations at $d x=50 \mathrm{~km}$ horizontal resolution produce significantly different results from $d x=20 \mathrm{~km}$ resolutions, even when the horizontal and vertical viscosities are held constant. They also report that changing the horizontal resolution had the most effect on mixing. It is difficult to justify that for the MPAS-Ocean results. For the highest vertical resolution of $d z=15 \mathrm{~m}$, at a constant vertical and horizontal viscosity, the three horizontal resolutions (finest to coarsest) give approximately $55 \%, 50 \%$, and $43 \%$ of the initial buoyancy value. For the highest horizontal resolution of $2.5 \mathrm{~km}$, at a constant vertical and horizontal viscosity, the four vertical resolutions (finest to coarsest) give approximately $55 \%, 54 \%, 47 \%, 37 \%$ of the initial buoyancy value. This suggests that changing vertical and horizontal resolution both significantly affect mixing. Additionally, the mixing is also largely affected by vertical viscosity (and horizontal 
viscosity to a much lesser extent). However, it is true that the mixing for any simulation run at $d x=50 \mathrm{~km}$ is significantly different because it is so under-resolved. It is also important to note that Legg et al. (2006) states that the physical case chosen here (Case 1 from Legg et al. (2006) ) might be slightly less sensitive to resolution than physical cases with higher Richardson numbers (such as cases with a weaker inflow density anomaly, i.e. less dense inflow).

Also in Riemenschneider and Legg (2007), the MITgcm was run without the use of any mixing parameterizations at a resolution of $d x=2.5 \mathrm{~km}$ in the horizontal and $d z=25 \mathrm{~m}$ in the vertical for a regional study of the Faroe Bank Channel. Good agreement was found at this resolution with observations when comparing the structure of the plume and the magnitude of the entrainment, which indicates that for realistic overflows, $10 \mathrm{~km}$ horizontal resolution might not be enough. 


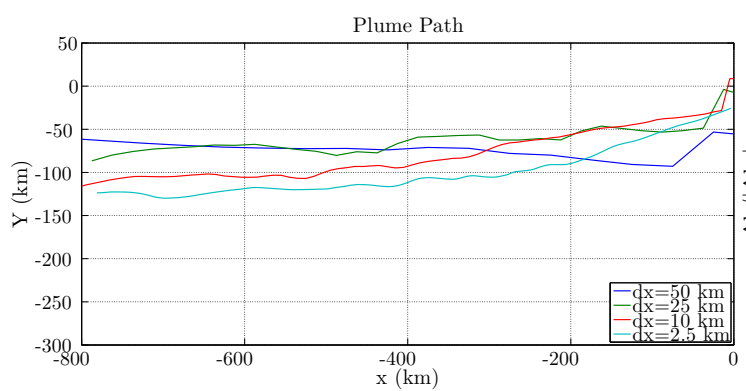

(a)

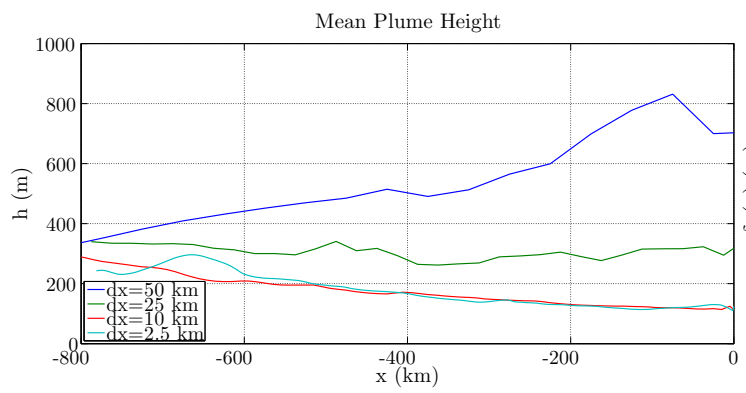

(c)

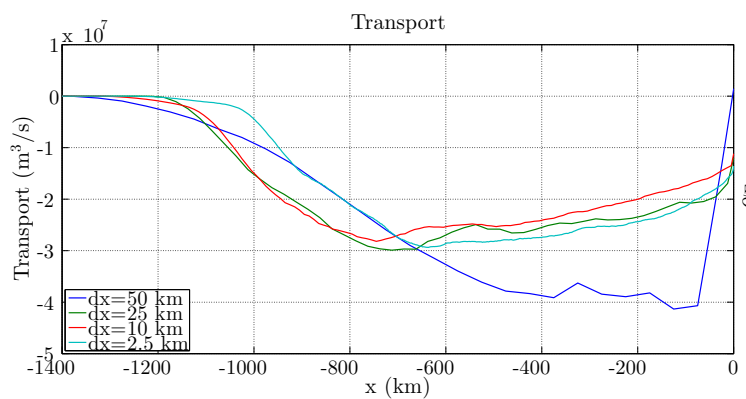

(e)

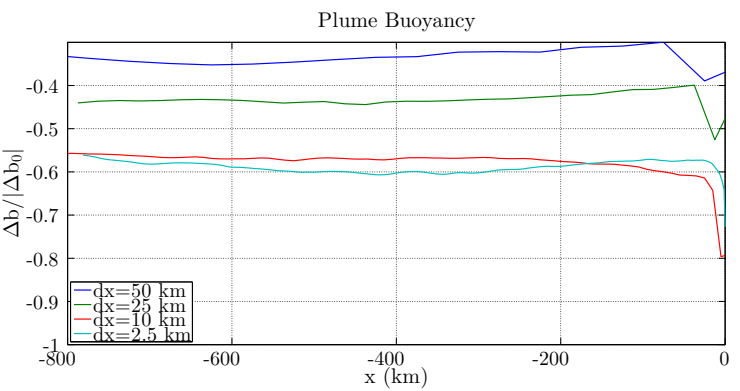

(b)

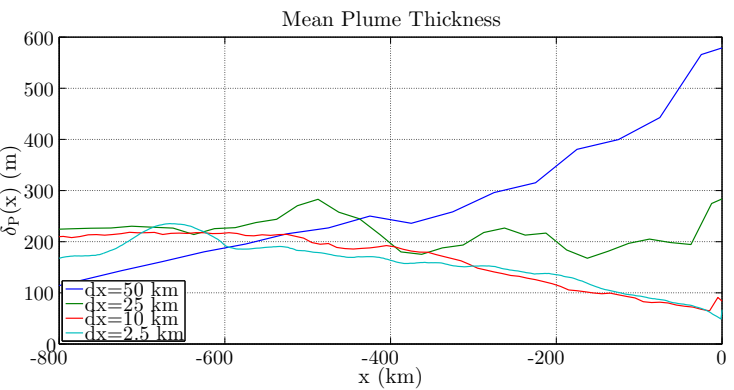

(d)

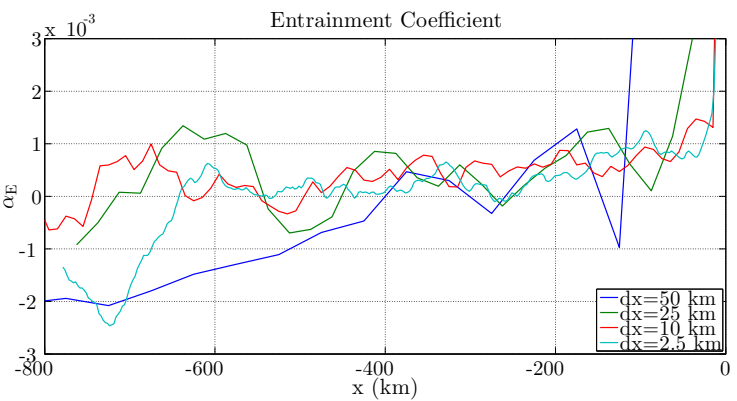

(f)

Figure 12: Plume path, plume buoyancy, mean plume height, mean plume thickness, transport, and entrainment coefficient for a constant vertical resolution of $d z=60 \mathrm{~m}$, z-star PBC, constant horizontal viscosity, $\nu_{h}=5 \mathrm{~m}^{2} / \mathrm{s}$ and vertical viscosity, $\nu_{v}=0.05 \mathrm{~m}^{2} / \mathrm{s}$, for all four horizontal resolutions $(d x=2.5,10,25,50 \mathrm{~km})$. All metrics are time averaged over the period day 22 to day 40 . 
The sensitivity to horizontal viscosity was explored and the range of horizontal viscosity parameters tested can be found in Table 4. Since the results are significantly less sensitive to horizontal viscosity compared to vertical viscosity, which matches Legg et al. (2008), a full isolated horizontal viscosity parameter study is not presented here.

\subsection{Sensitivity to Vertical Grid Type}

MPAS-Ocean uses the ALE method in the vertical, which has been validated in a variety of configurations (Petersen et al. 2015). The primary grids compared in this study are: z-star with full cells; z-star with PBCs; and sigma coordinates. In addition, some z-level with PBC cases were run for validation and comparison. Most MPAS-Ocean real-world simulations to date have used z-star with PBCs (Ringler et al. 2013).

Fig. 13 shows bottom tracer concentration for three of the vertical grid types: z-star full cell, z-star PBC, and sigma. These tiled plots give a qualitative look at the differences in vertical grid types at a variety of vertical viscosities. The results for z-star full cell and z-star PBC are similar, especially compared to the sigma results, which show much less mixing (as was shown in Ezer and Mellor (2004); Wang et al. (2008)). The z-type vertical coordinate simulations, even with PBCs, induce spurious mixing due to the stair-step representation of the bottom topography, which is why the z-type coordinate results have more mixing than the sigma coordinate results. This is particularly evident by looking at the 1D metrics in Fig. 14. which compares all four of the vertical grid types. The three z-type vertical coordinate cases are very close in almost all of the 1D metrics, but the z-star full cell case does result in a slower (Fig. 14a), thicker plume (Fig. 14c) that pulls up off the slope more than the others (Fig. 14c). Changes from z-level to z-star were not expected, so these results are reassuring. The sigma case shows a steeper plume path (Fig. 14a), a less dilute plume (Fig. 14b), a thinner plume (Fig. 14d) that is closer to the slope (Fig. 14c), with less transport (Fig. 14e) and less entrainment in the first $200 \mathrm{~m}$ of the plume descent (Fig. 14f). These differences in the sigma case are all expected as there is clearly less mixing in the sigma simulations. 

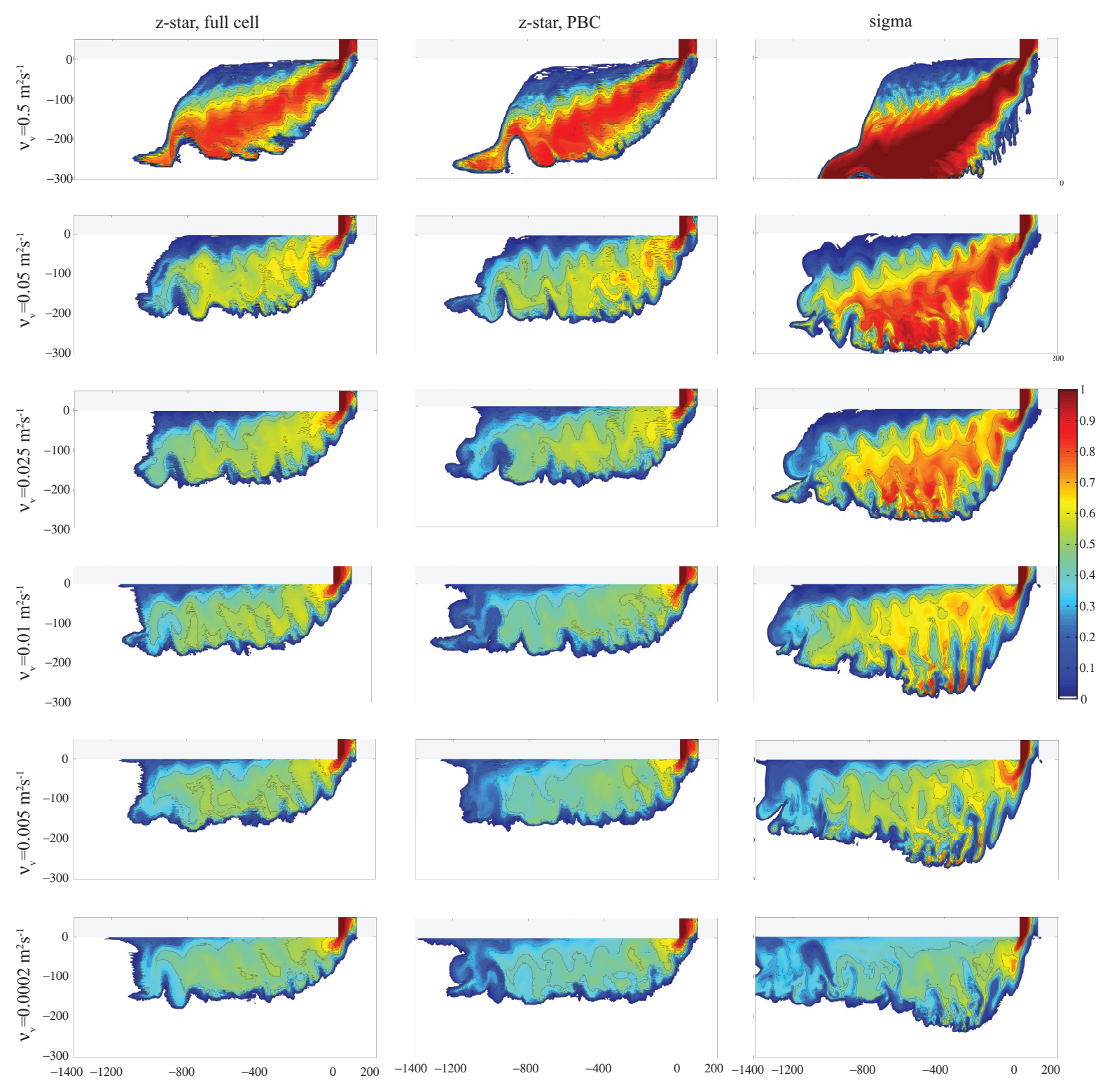

Figure 13: Bottom tracer concentration using a visualization thickness of $\Delta z_{p l o t}=60 \mathrm{~m}$ varying vertical viscosity for the three different vertical grid types of z-star, z-star PBC, and sigma. All simulations use $d x=2.5 \mathrm{~km}, 60$ layers ( $d z=60 \mathrm{~m}$ for $\mathrm{z}$ coordinates), and all images show day 40 . 


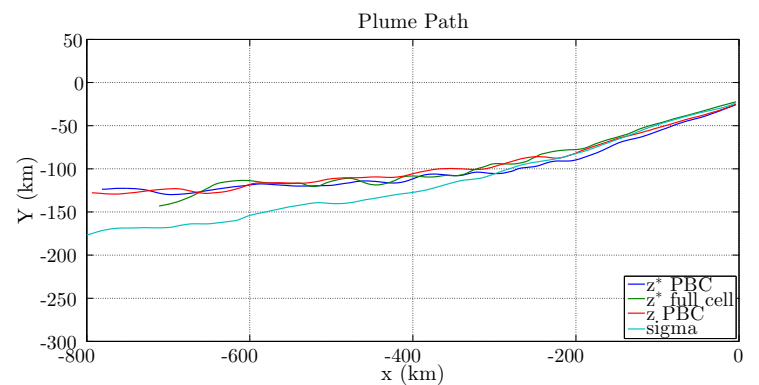

(a)

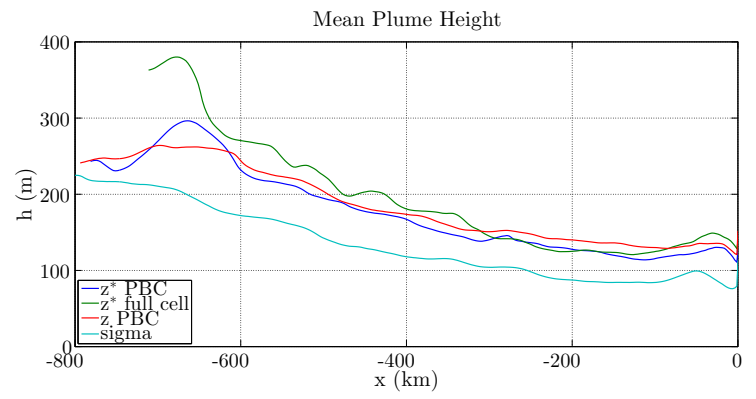

(c)

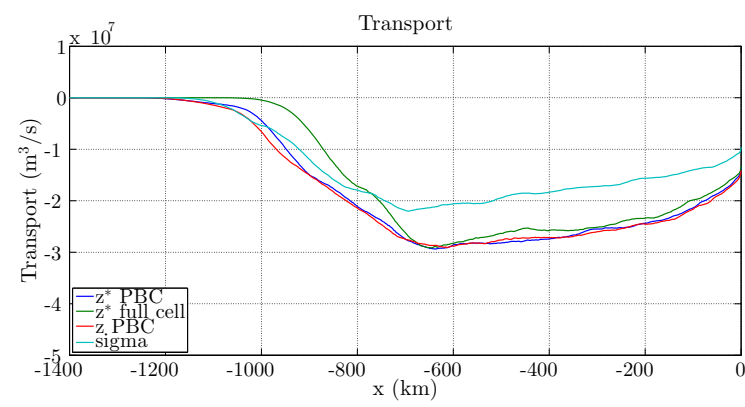

(e)

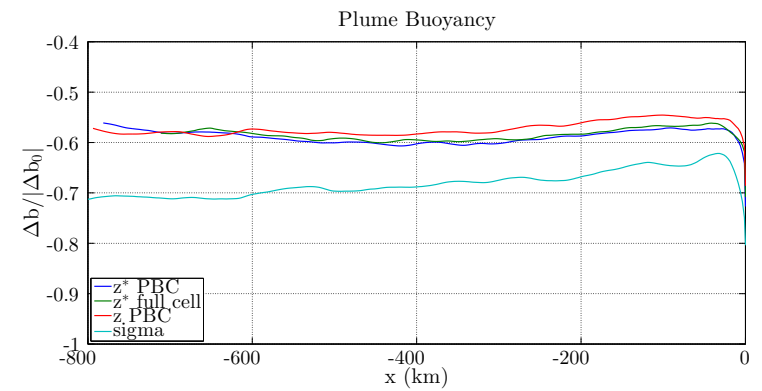

(b)

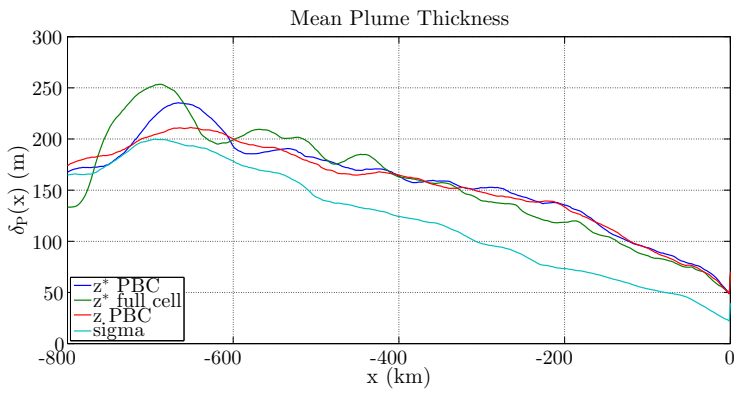

(d)

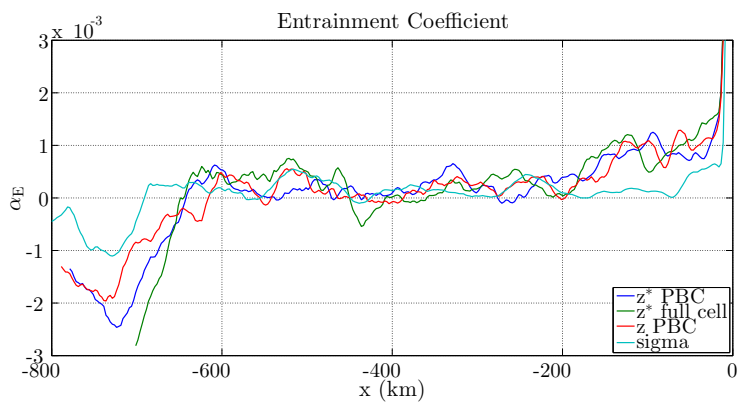

(f)

Figure 14: Plume path, plume buoyancy, mean plume height, mean plume thickness, transport, and entrainment coefficient plotted for all four vertical grid types (z-star PBC, z-star full cel, z-coordinate PBC, and sigma) using the base case, $d x=2.5 \mathrm{~km}$, and 60 vertical layers $(d z=60 \mathrm{~m}$ for $\mathrm{z}$ coordinates). All metrics are time-averaged over the period of day 22 to day 40 . 
One interesting feature of the sigma case results is that even at low horizontal resolution, eddies are present when the vertical resolution is high enough. Similar results were found with the isopycnal model used in Legg et al. (2006). The $10 \mathrm{~km}$ isopycnal results had more eddy structure than the $10 \mathrm{~km}$ z-coordinate calculations. This is a significant difference from the z-star PBC results. Also, the previous work of Ezer and Mellor (2004) and Wang et al. (2008) has shown that sigma coordinate simulations are less dependent on horizontal resolution than z-coordinate models. This study showed that to be true, which can be seen in the scalar plots in Fig. 9. The sigma coordinate model's mean final buoyancies were all very close for all three horizontal resolutions. Additionally, the sigma coordinate simulations were also less sensitive to changes in vertical resolution than the z-type simulations, which can be seen in Fig. 9b. This is mostly because spurious mixing is so low for all sigma runs, even at low resolution. However, the sigma coordinate simulations have higher mean final buoyancy than the HIM simulations, indicating that there is more mixing and entrainment in the MPAS-O sigma simulations than in the isopycnal HIM simulations. Although MPAS-O sigma does not have an explicit diapycnal mixing scheme, the vertical viscosity is an order of magnitude smaller in the sigma cases plotted (green dash line) in Fig. 9b compared to the z-star PBC cases. The vertical viscosity greatly changes the plume metrics in the sigma case, as can be seen in Fig. 16. For a vertical viscosity $\left(\nu_{v}=0.05 \mathrm{~m}^{2} / \mathrm{s}\right)$ equivalent to the z-coordinate simulations in Fig. 9b, the mean final buoyancy is approximately $70 \%$ its initial buoyancy value. This point is plotted in Fig. 16. This value shows that there is much less mixing in the sigma coordinate simulations compared to all other simulations, if the vertical viscosity is set equivalently.

Lastly, Fig. 9 shows how sigma results depend on vertical resolution for all three horizontal resolutions using both the initial angle of descent and mean final buoyancy metrics. This shows that at the two higher horizontal resolutions, sigma results are insensitive to changes in vertical resolution, especially compared to the z-coordinate results. However, at the coarsest horizontal resolution of $d x=50 \mathrm{~km}$, there is over a $5 \%$ change in mean final buoyancy between the coarsest and finest vertical resolution. The findings of Laanaia et al. (2010) found that there needed to be at least 5 sigma layers within the bottom boundary layer, which was approximately $30 \mathrm{~m}$ thick. For the four different sigma vertical resolution cases the sigma layers are distributed accordingly. For the 30 layer case, the layers are 120 $\mathrm{m}$ thick in the basin and $20 \mathrm{~m}$ thick in the embayment. For the 60 layer case, the layers are $60 \mathrm{~m}$ thick in the basin and $10 \mathrm{~m}$ thick in the embayment. For the 120 layer case, the layers are $30 \mathrm{~m}$ thick in the basin and $5 \mathrm{~m}$ thick in the embayment. For the 240 layer case, the layers are $15 \mathrm{~m}$ thick in the basin and $2.5 \mathrm{~m}$ thick in the embayment. The bottom boundary layer is probably well resolved in all four vertical resolution cases near the embayment, but is likely under-resolved in the basin for the two coarsest vertical resolution cases. The metrics in Fig. 9 do not indicate that any combination of vertical or horizontal resolution for the sigma coordinate simulations are under resolved, as there is very little difference in both initial angle of descent and mean final buoyancy as vertical resolution is varied.

Down-slope bottom Ekman transport is a metric that can be used to understand the transport added due to the bottom Ekman boundary layer. For this metric, y-transport is calculated similar to (8), except the meridional velocity is integrated in the $\mathrm{x}$ direction rather than the zonal velocity being integrated in the y direction. Transport is z-integrated in the same way. Y-transport is calculated for five different vertical viscosity cases $\left(\nu_{v}=\right.$ 
$\left.0.5,0.05,0.025,0.01,0.002 \mathrm{~m}^{2} \mathrm{~s}^{-1}\right)$ and for a case run with vertical viscosity set to zero. The base case configuration is used for all other numerical parameters. As defined by Ezer (2005), down-slope bottom Ekman transport is calculated by subtracting off the y-transport for the case run with zero vertical viscosity (assumed no Ekman layer and zero Ekman transport) from the y-transport for cases run with non-zero vertical viscosity. This metric shows only the induced transport from the bottom Ekman layer as the plume moves down the slope.

As was found in Ezer (2005), as vertical viscosity increases, Ekman transport and downslope flow are enhanced. This is true for both z-star PBC and sigma coordinate solutions and is shown in Figure 15. There are two separate processes by which increases in vertical viscosity enhance the down-slope flow: (1) a reduction in turbulent mixing that leads to sharper initial angles of descent and denser plumes, and (2) an enhancement of the drag between vertical layers, which induces transport $90^{\circ}$ to the left of the flow. Whereas only the latter should be attributed to Ekman processes, both of these effects are captured by the calculation of Ekman transport used here.

The maximum Ekman transport is larger for z-star PBC than for sigma coordinate cases, however, the Ekman transport is larger for the sigma cases further downslope than for the zstar PBC cases, as expected from looking at Figure 13. Changing vertical resolution instead of vertical viscosity has the opposite effect on down-slope bottom Ekman transport. As $d z$ decreases, there is less mixing, which leads to a less diluted plume, thus, the down-slope Ekman transport increases. The down-slope bottom Ekman transport does not vary as much as $d z$ changes, compared changing vertical viscosity. For z-star PBC, the maximum y-transport is approximately $-15.5 \mathrm{~Sv}$ (for $d z=60 \mathrm{~m}$ ), $-14.5 \mathrm{~Sv}$ (for $d z=30 \mathrm{~m}$ ), and $-13 \mathrm{~Sv}$ (for $d z=30 \mathrm{~m}$ ). However, further down the slope at approximately $y=-150 \mathrm{~km}, d z=120 \mathrm{~m}$ has a y-transport of approximately $-4 \mathrm{~Sv}$ and all three finer resolution have a y-transport of about $-8 \mathrm{~Sv}$. For sigma, the y-transport is very similar for all vertical resolutions, except that the 30 layer (coarsest resolution) case has about $3 \mathrm{~Sv}$ more of transport at the bottom half of the slope.

These effects of vertical resolution and vertical viscosity on the down-slope bottom Ekman transport can be directly linked to the vertical grid Reynolds number. Decreasing vertical viscosity and increasing vertical resolution both lead to more Ekman transport due to a better resolved Ekman bottom boundary layer. This general trend was found in these results, however, there are some outliers. This is likely due to the eddying behavior induced by various different processes that is explained in Sec. 5.1.3.

Fig. 16 shows scalar metrics comparing the different vertical grid types for a range of vertical and horizontal viscosities. These plots show that sigma simulations are definitely less sensitive to horizontal viscosity than z-star PBC simulations are for the initial angle of descent. However, mean final buoyancy sensitivity to horizontal viscosity is similar for both vertical grid types. Overall, all the vertical grid types are much more sensitive to vertical viscosity than horizontal viscosity, as was found in Legg et al. (2008), where this was shown for MITgcm simulations and speculated for sigma coordinate simulations.

\section{Conclusions and Discussion}

This study, which focuses on the sensitivity of overflow simulations to vertical grid types, resolution, and viscosity using MPAS-Ocean, is an extension and generalization of previous 


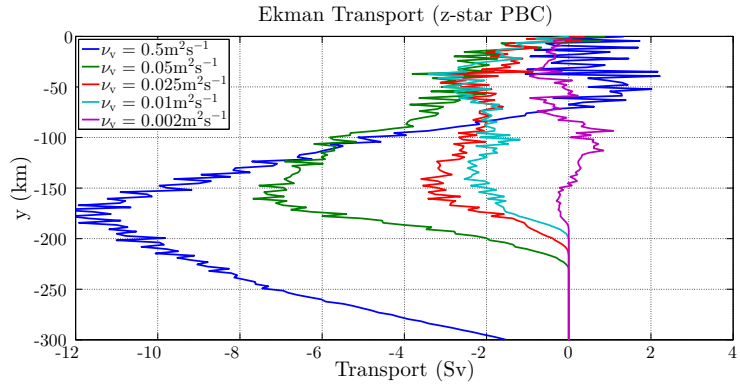

(a)

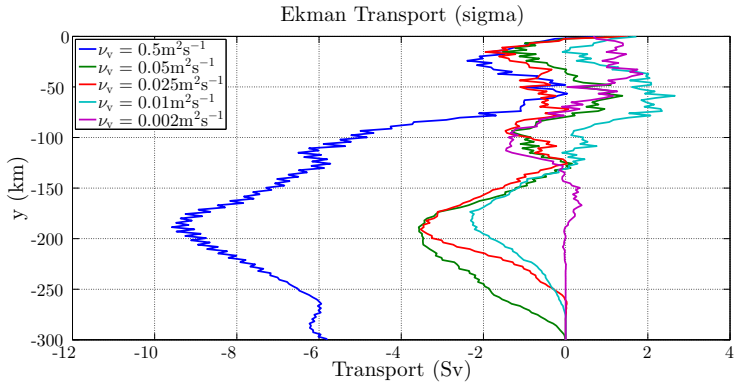

(b)

Figure 15: Ekman transport at various vertical viscosities for $d x=2.5 \mathrm{~km}$ horizontal resolution and $d z=$ $60 \mathrm{~m}$ vertical resolution for z-star PBCs (left) and sigma. Metrics are time-averaged over the period of day 22 to day 40.
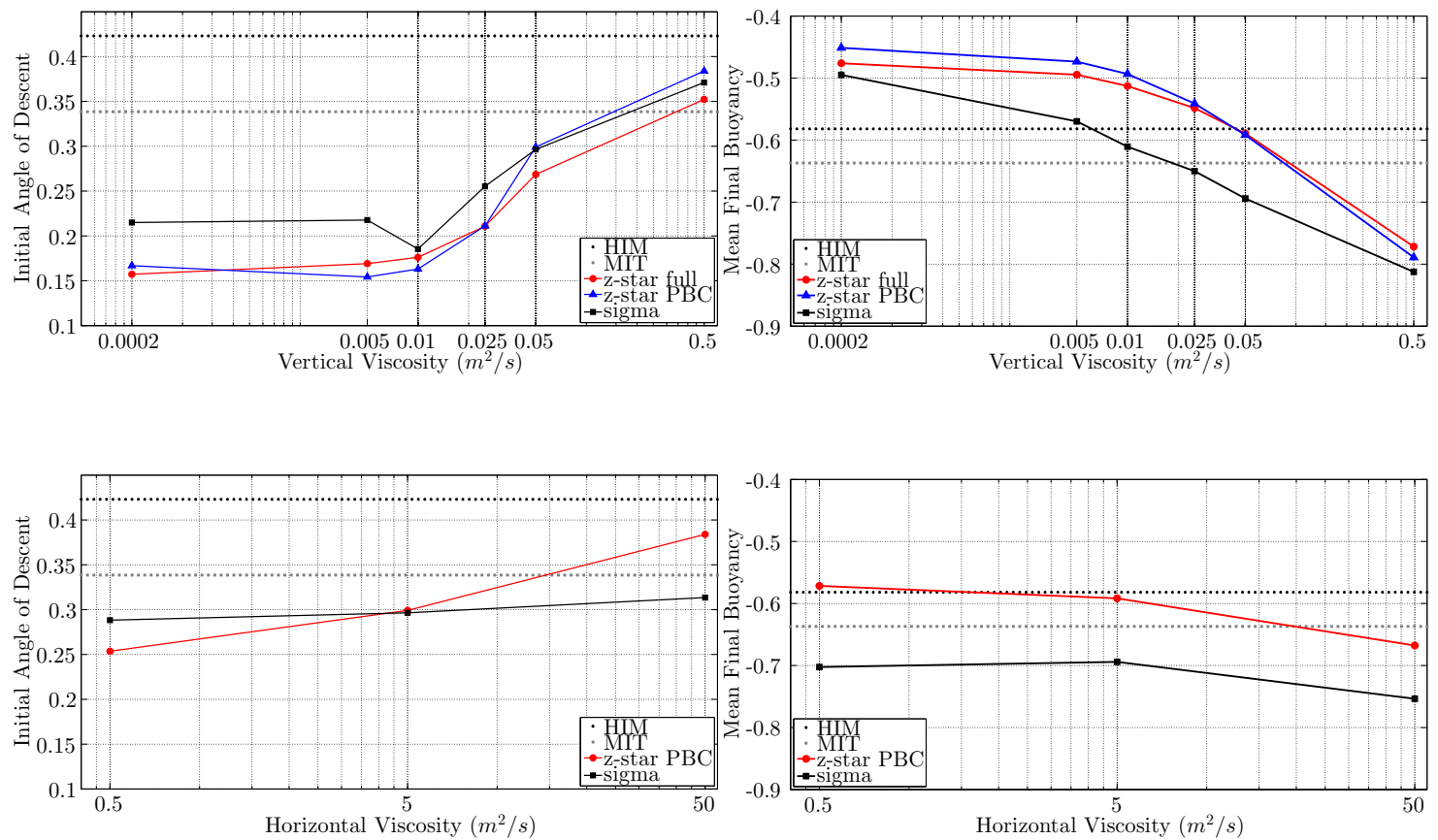

Figure 16: Averaged scalar metrics, showing initial angle of descent (left column) and mean final buoyancy (right column) varying vertical viscosity (top row) and horizontal viscosity (bottom row) for MPAS-Ocean z-coordinates and sigma coordinate with MITgcm z-coordinate and HIM isopycnal coordinate. These cases are all run in the base case configuration, which is a $d z=60 \mathrm{~m}$ and $d x=2.5 \mathrm{~km}$, changing only the one parameter independently.

work by Özgökmen and Chassignet (2002); Özgökmen et al. (2004a); Anderson (2004); Ezer and Mellor (2004); Ezer (2005); Legg et al. (2006 2008); Wang et al. (2008); Bates et al. (2012).

Development of MPAS-Ocean began in 2010. It was first released to the public in 2013 and the first publication, on high-resolution global ocean simulations, appeared that same year (Ringler et al. 2013). Idealized test cases with specific initial conditions and parameters are 
an essential part of the development and validation process. For the DOME test case, MPASOcean produced nearly identical results as MITgcm and HIM under the same conditions. It is important to emphasize that all simulations presented here using MPAS-Ocean were run with no mixing parameterizations and no overflow parameterizations.

The parameter study presented in Section 5 thoroughly examines the sensitivity of the overflow simulations to vertical and horizontal numerical parameters, including viscosity, resolution, and grid Reynolds number, as well as vertical grid type. The highlights of the full parameter study are summarized here.

\subsection{Vertical Parameters}

Overflow simulations are highly sensitive to changing vertical viscosity, which has been shown in Legg et al. (2008). However, it is shown here that the sensitivity to vertical viscosity is different at low and high resolution. In particular, at high vertical resolution, high vertical viscosity results in stronger eddies. Also, at low resolution, metrics are less sensitive to vertical viscosity than at higher resolution. This is particularly true for plume path.

Sensitivity of overflow simulations to vertical resolution as an independent controlling factor of overflows within the DOME test case has not been done in any of the previous studies. This study has shown that plume path and plume buoyancy are nearly as sensitive to vertical resolution as they are to vertical viscosity. Specifically, there is higher sensitivity to vertical resolution when smaller vertical viscosity is used, compared with larger vertical viscosity cases. This is particularly true for plume buoyancy.

At low horizontal resolution $(d x=50 \mathrm{~km})$, there is very little sensitivity to vertical resolution or viscosity. At medium and higher horizontal resolution ( $d x=10 \mathrm{~km}$ and $2.5 \mathrm{~km})$ mixing characteristics improve from $d z=120 \mathrm{~m}$ to $d z=60 \mathrm{~m}$ vertical resolution, i.e. there is less spurious mixing, less entrainment of ambient fluid into the plume, and product water is denser. Mixing characteristics do not change much from $d z=60 \mathrm{~m}$ to $d z=30 \mathrm{~m}$ and $15 \mathrm{~m}$. In this range, vertical viscosity provides more control over the final buoyancy and plume path. In real-world simulations, higher vertical resolutions may still be needed for better representation of bottom topography.

\subsection{Horizontal Parameters}

There is little sensitivity to horizontal viscosity, which matches the conclusion of Legg et al. (2008). The main rationale provided in Legg et al. (2008) is that vertical viscosity strongly influences the thickness of the Ekman layer, where horizontal viscosity does not. This is why results were indifferent to the horizontal viscosity used, as long as the horizontal viscosity was small enough to permit eddies. A horizontal resolution of $d x=50 \mathrm{~km}$, which is larger than the Rossby Radius of deformation, provides a crude representation of the overall plume structure, but spurious mixing and entrainment is high, regardless of the viscosity or vertical resolution. At the recommended vertical resolution of $d z=60 \mathrm{~m}$, horizontal resolutions of $d x=10 \mathrm{~km}$ and $d x=2.5 \mathrm{~km}$ are nearly identical for all four vertical viscosities tested for the initial angle of descent and mean plume buoyancy metrics. Thus, $d x=10 \mathrm{~km}$ is sufficient to resolve the mesoscale dynamics of this type of overflow, which has slopes and density gradients that mimic overflows in the North Atlantic. Whereas others have stated that horizontal resolution plays a big role in mixing behavior (Legg et al. 2006; Wang et al. 2008), this study suggests horizontal resolution alone does not significantly affect mixing 
below $d x=10 \mathrm{~km}$. Rather, mixing is most strongly affected by changes in vertical viscosity, and to a lesser degree by vertical resolution.

\subsection{Vertical Grid Type}

Sigma results are less sensitive to variations in vertical and horizontal resolution than z-coordinate results, which was also found in Ezer and Mellor (2004); Wang et al. (2008). Sigma coordinates do a much better job of capturing the overall plume structure (also shown in Ezer and Mellor (2004); Wang et al. (2008)), but here it is shown that they are also able to capture eddies at the lowest horizontal resolution of $d x=50 \mathrm{~km}$. As expected (Ezer and Mellor 2004; Özgökmen et al. 2004b; Wang et al. 2008), sigma produces much less mixing than z-coordinates. In fact, sigma can produce lower ranges of mixing than possible with any configuration of z-coordinates. As was speculated in Legg et al. (2008), this work shows that sigma coordinate simulations are as sensitive to vertical viscosity as z-coordinate simulations.

\subsection{Recommendations for Ocean Global Circulation Models}

The most substantial findings from this study include a stronger sensitivity of the mixing to vertical resolution (within the full range tested $d z=120,60,30,15 \mathrm{~m}$ ) than horizontal resolution (within the range $d x=10,2.5 \mathrm{~km}$ ), a qualitative behavior shift in the overflow dynamics between horizontal resolutions of $50 \mathrm{~km}$ and $10 \mathrm{~km}$, and a stronger dependence on vertical viscosity at finer resolutions. Our primary recommendation for modelers is that a horizontal resolution of $10 \mathrm{~km}$ and a vertical resolution of $60 \mathrm{~m}$ are sufficient for these types of overflows, as long as high-resolution topography is not required. Once such resolutions are attainable, vertical viscosity is the primary control over the mixing (when considering only what was tested in this work), which in turn sets the characteristics of the product water. Additionally, this study shows that higher resolution captures more of the dynamics of overflows, such that overflow parameterizations that have been tuned to low-resolution horizontal grids (e.g. $1^{\circ}$ global grid) will likely need to be reconfigured to work at highresolution $\left(1 / 10^{\circ}\right.$ or finer). Since spurious mixing is reduced but not removed by increasing resolution, overflow parameterizations will still need to be used.

Finally, as computational power increases and the standard grids for climate models become finer, vertical viscosity will play an increasingly important role in accurately representing the plume evolution and mixing characteristics of oceanic overflows. Special attention and future studies should be devoted to these issues going forward, since getting overflows right is vital for accurate representation of large-scale circulation in the ocean.

\subsection{Future Work with Realistic Overflow Configurations}

There has been previous work looking at global realistic overflow simulations including Riemenschneider and Legg (2007); Chang et al. (2009); Seim et al. (2010); Snow et al. (2015). This study focuses on how the numerical parameters in MPAS-Ocean affect overflow simulations in an idealized domain. All of the simulations presented here have been run on a uniform grid using hexagonal cells. The advantage of MPAS-Ocean is that it utilizes an unstructured horizontal mesh capable of non-uniform resolution. Adding horizontal refinement in overflow regions may improve overflow characteristics in global simulations with realistic topography. This will be the focus of our work in the near future. MPAS-Ocean provides a natural framework for this type of study, as high horizontal resolution in multiple overflow regions may be nested within a low resolution global domain. 


\section{Acknowledgements}

Simulations were conducted using LANL Institutional Computing resources and Fairfield University's Mithra computing cluster. S. M. Reckinger was supported by the Henry Luce Foundation through the Clare Boothe Luce Professorship. M. Petersen was supported by the Earth System Modeling Program of the Office of Biological and Environmental Research within the US Department of Energy's Office of Science. A special thanks to Sonya Legg for her feedback, insight, and for providing us with MITgcm and HIM results to compare against. The authors would also like to thank the two anonymous reviewers for their thorough review and insight, which improved the manuscript greatly.

Adcroft, A., Campin, J.-M., 2004. Rescaled height coordinates for accurate representation of free-surface flows in ocean circulation models. Ocean Modelling 7 (3), 269-284.

Adcroft, A., Hill, C., Marshall, J., 1997. Representation of topography by shaved cells in a height coordinate ocean model. Monthly Weather Review 125 (9), 2293-2315.

Anderson, W. G., 2004. Oceanic sill-overflow systems: Investigations and simulation with the Poseidon ocean general circulation model. Ph.D. thesis, George Mason University.

Baringer, M. O., Price, J. F., 1997. Mixing and spreading of the mediterranean outflow. Journal of Physical Oceanography 27 (8), 1654-1677.

Bates, M. L., Griffies, S. M., England, M. H., 2012. A dynamic, embedded lagrangian model for ocean climate models, part ii: Idealised overflow tests. Ocean Modelling 59, 60-76.

Baumert, H. Z., Simpson, J., Sündermann, J. (Eds.), 2005. Marine turbulence: theories, observations, and models. Vol. 1. Cambridge University Press.

Beckmann, A., Döscher, R., 1997. A method for improved representation of dense water spreading over topography in geopotential-coordinate models. Journal of Physical Oceanography 27 (4), 581-591.

Blumberg, A. F., Mellor, G. L., 1987. A description of a three-dimensional coastal ocean circulation model. Three-dimensional coastal ocean models, 1-16.

CAMPIN, J.-M., Goosse, H., 1999. Parameterization of density-driven downsloping flow for a coarse-resolution ocean model in z-coordinate. Tellus A 51 (3), 412-430.

Cenedese, C., Whitehead, J. A., Ascarelli, T., Ohiwa, M., 2004. A dense current flowing down a sloping bottom in a rotating fluid. Journal of Physical Oceanography 34 (1), 188-203.

Chang, Y. S., Garraffo, Z. D., Peters, H., Özgökmen, T. M., 2009. Pathways of nordic overflows from climate model scale and eddy resolving simulations. Ocean Modelling 29 (1), $66-84$.

Chassignet, E. P., Arango, H., Dietrich, D., Ezer, T., Ghil, M., Haidvogel, D. B., Ma, C.-C., Mehra, A., Paiva, A. M., Sirkes, Z., 2000. Damee-nab: the base experiments. Dynamics of Atmospheres and Oceans 32 (3), 155-183. 
Ellison, T., Turner, J., 1959. Turbulent entrainment in stratified flows. Journal of Fluid Mechanics 6 (03), 423-448.

Ezer, T., 2005. Entrainment, diapycnal mixing and transport in three-dimensional bottom gravity current simulations using the mellor-yamada turbulence scheme. Ocean Modelling 9 (2), 151-168.

Ezer, T., Mellor, G. L., 2004. A generalized coordinate ocean model and a comparison of the bottom boundary layer dynamics in terrain-following and $i n_{i} i_{i}, z_{i} / i_{i}$-level grids. Ocean Modelling 6 (3), 379-403.

Foster, T. D., Carmack, E. C., 1976. Frontal zone mixing and antarctic bottom water formation in the southern weddell sea. Deep Sea Research and Oceanographic Abstracts 23 (4), $301-317$. URL http://www.sciencedirect.com/science/article/pii/001174717690872X

Gent, P. R., McWilliams, J. C., 1990. Isopycnal mixing in ocean circulation models. Journal of Physical Oceanography 20 (1), 150-155.

Gent, P. R., Willebrand, J., McDougall, T., McWilliams, J. C., 1995. Parameterizing eddy-induced tracer transports in ocean general circulation models. Journal of Physical Oceanography 25 (25), 463-474.

Girton, J. B., Sanford, T. B., 2003. Descent and modification of the overflow plume in the denmark strait*. Journal of Physical Oceanography 33 (7), 1351-1364.

Gordon, A. L., Zambianchi, E., Orsi, A., Visbeck, M., Giulivi, C. F., Whitworth, T., Spezie, G., 2004. Energetic plumes over the western ross sea continental slope. Geophysical Research Letters 31 (21).

Haidvogel, D. B., Arango, H. G., Hedstrom, K., Beckmann, A., Malanotte-Rizzoli, P., Shchepetkin, A. F., 2000. Model evaluation experiments in the north atlantic basin: simulations in nonlinear terrain-following coordinates. Dynamics of Atmospheres and Oceans 32 (3), 239-281.

Hallberg, R., 2000. Time integration of diapycnal diffusion and richardson number-dependent mixing in isopycnal coordinate ocean models. Monthly Weather Review 128 (5), 14021419.

Higdon, R. L., 2005. A two-level time-stepping method for layered ocean circulation models: further development and testing. Journal of Computational Physics 206 (2), 463-504.

Ilicak, M., Adcroft, A. J., Griffies, S. M., Hallberg, R. W., 2012. Spurious dianeutral mixing and the role of momentum closure. Ocean Modelling 45, 37-58.

Ilicak, M., Özgökmen, T. M., Peters, H., Baumert, H. Z., Iskandarani, M., 2008. Performance of two-equation turbulence closures in three-dimensional simulations of the red sea overflow. Ocean Modelling 24 (3), 122-139. 
IPCC, 2013. Climate Change 2013: The Physical Science Basis. Contribution of Working Group I to the Fifth Assessment Report of the Intergovernmental Panel on Climate Change. Cambridge University Press, Cambridge, United Kingdom and New York, NY, USA.

URL www.climatechange2013.org

Jackson, L., Hallberg, R., Legg, S., 2008. A parameterization of shear-driven turbulence for ocean climate models. Journal of Physical Oceanography 38 (5), 1033-1053.

Käse, R. H., Girton, J., Sanford, T., 2003. Structure and variability of the denmark strait overflow: Model and observations. Journal of Geophysical Research: Oceans (1978-2012) 108 (C6).

Killworth, P. D., Edwards, N. R., 1999. A turbulent bottom boundary layer code for use in numerical ocean models. Journal of Physical Oceanography 29 (6), 1221-1238.

Laanaia, A., Wirth, A., Molines, J. M., Barnier, B., Verron, J., 2010. On the numerical resolution of the bottom layer in simulations of oceanic gravity currents. Ocean Science 6, $563-572$.

Lane-Serff, G. F., Baines, P. G., 1998. Eddy formation by dense flows on slopes in a rotating fluid. Journal of Fluid Mechanics 363, 229-252.

Large, W. G., Gent, P. R., 1999. Validation of vertical mixing in an equatorial ocean model using large eddy simulations and observations. Journal of Physical Oceanography 29 (3), 449-464.

Large, W. G., McWilliams, J. C., Doney, S. C., 1994. Oceanic vertical mixing: A review and a model with a nonlocal boundary layer parameterization. Reviews of Geophysics 32 (4), 363-403.

Leclair, M., Madec, G., 2011. -coordinate, an arbitrary lagrangian-eulerian coordinate separating high and low frequency motions. Ocean Modelling 37 (3), 139-152.

Legg, S., 2012. Overflows and convectively-driven flows. Buoyancy-driven Flows, 203-239.

Legg, S., Ezer, T., Jackson, L., Briegleb, B. P., Danabasoglu, G., Large, W. G., Wu, W., Chang, Y., Ozgokmen, T. M., Peters, H., et al., 2009. Improving oceanic overflow representation in climate models: the gravity current entrainment climate process team. Bulletin of the American Meteorological Society.

Legg, S., Hallberg, R. W., Girton, J. B., 2006. Comparison of entrainment in overflows simulated by z-coordinate, isopycnal and non-hydrostatic models. Ocean Modelling 11 (1), 69-97.

Legg, S., Jackson, L., Hallberg, R., 2008. Eddy-resolving modeling of overflows. Ocean Modeling in an Eddying Regime, 63-81. 
Maltrud, M. E., McClean, J. L., 2005. An eddy resolving global 1/10^o ocean simulation. Ocean Modelling 8, 31-54.

Mauritzen, C., Price, J., Sanford, T., Torres, D., 2005. Circulation and mixing in the faroese channels. Deep Sea Research Part I: Oceanographic Research Papers 52 (6), 883-913.

Meincke, J., Le Provost, C., Willebrand, J., 2001. Dynamo. Progress in Oceanography 48 (2), $121-122$.

Muench, R., Padman, L., Gordon, A., Orsi, A., 2009. A dense water outflow from the ross sea, antarctica: Mixing and the contribution of tides. Journal of Marine Systems 77 (4), 369-387.

Özgökmen, T. M., Chassignet, E. P., 2002. Dynamics of two-dimensional turbulent bottom gravity currents. Journal of Physical Oceanography 32 (5), 1460-1478.

Özgökmen, T. M., Fischer, P. F., Duan, J., Iliescu, T., 2004a. Entrainment in bottom gravity currents over complex topography from three-dimensional nonhydrostatic simulations. Geophysical Research Letters 31 (13).

Özgökmen, T. M., Fischer, P. F., Duan, J., Iliescu, T., 2004b. Three-dimensional turbulent bottom density currents from a high-order nonhydrostatic spectral element model. Journal of Physical Oceanography 34 (9), 2006-2026.

Pacanowski, R., Philander, S., 1981. Parameterization of vertical mixing in numerical models of tropical oceans. Journal of Physical Oceanography 11 (11), 1443-1451.

Papadakis, M. P., Chassignet, E. P., Hallberg, R. W., 2003. Numerical simulations of the mediterranean sea outflow: Impact of the entrainment parameterization in an isopycnic coordinate ocean model. Ocean modelling 5 (4), 325-356.

Peters, H., Johns, W. E., 2005. Mixing and entrainment in the red sea outflow plume. part ii: Turbulence characteristics. Journal of physical oceanography 35 (5), 584-600.

Peters, H., Johns, W. E., Bower, A. S., Fratantoni, D. M., 2005. Mixing and entrainment in the red sea outflow plume. part i: Plume structure. Journal of Physical Oceanography $35(5), 569-583$.

Petersen, M. R., Jacobsen, D. W., Ringler, T. D., Hecht, M. W., Maltrud, M. E., 2015. Evaluation of the arbitrary lagrangian-eulerian vertical coordinate method in the mpasocean model. Ocean Modelling 86 (0), 93 - 113. URL http://www.sciencedirect.com/science/article/pii/S1463500314001796

Rauscher, S. A., Ringler, T. D., Skamarock, W. C., Mirin, A. A., 2013. Exploring a global multiresolution modeling approach using aquaplanet simulations*. Journal of Climate 26 (8), 2432-2452.

Riemenschneider, U., Legg, S., 2007. Regional simulations of the faroe bank channel overflow in a level model. Ocean Modelling 17 (2), 93-122. 
Ringler, T., Ju, L., Gunzburger, M., Dec. 2008. A multiresolution method for climate system modeling: application of spherical centroidal Voronoi tessellations. Ocean Dynamics 58, 475-498.

Ringler, T., Petersen, M., Higdon, R. L., Jacobsen, D., Jones, P. W., Maltrud, M., 2013. A multi-resolution approach to global ocean modeling. Ocean Modelling 69 (C), - . URL http://www.sciencedirect.com/science/article/pii/S1463500313000760

Ringler, T. D., 2011. Momentum, vorticity and transport: Considerations in the design of a finite-volume dynamical core. In: Lauritzen, P., Jablonowski, C., Taylor, M., Nair, R. (Eds.), Numerical Techniques for Global Atmospheric Models. Vol. 80 of Lecture Notes in Computational Science and Engineering. Springer Berlin Heidelberg, pp. 143-183.

Ringler, T. D., Thuburn, J., Klemp, J. B., Skamarock, W. C., May 2010. A unified approach to energy conservation and potential vorticity dynamics for arbitrarily structured C-grids. Journal of Computational Physics 229, 3065-3090.

Roberts, M., Wood, R., 1997. Topographic sensitivity studies with a bryan-cox-type ocean model. Journal of Physical Oceanography 27 (5), 823-836.

Seim, K. S., Fer, I., Berntsen, J., 2010. Regional simulations of the faroe bank channel overflow using a $\sigma$-coordinate ocean model. Ocean Modelling 35 (1), 31-44.

Skamarock, W. C., Gassmann, A., 2011. Conservative transport schemes for spherical geodesic grids: High-order flux operators for ode-based time integration. Monthly Weather Review 139 (9), 2962-2975.

Skamarock, W. C., Klemp, J. B., Duda, M. G., Fowler, L. D., Park, S.-H., Ringler, T. D., 2012. A multiscale nonhydrostatic atmospheric model using centroidal voronoi tesselations and c-grid staggering. Monthly Weather Review 140 (9), 3090-3105.

Snow, K., Hogg, A. M., Downes, S. M., Sloyan, B. M., Bates, M. L., Griffies, S. M., 2015. Sensitivity of abyssal water masses to overflow parameterisations. Ocean Modelling 89, 84-103.

Song, Y. T., Chao, Y., 2000. An embedded bottom boundary layer formulation for zcoordinate ocean models. Journal of Atmospheric and Oceanic Technology 17 (4), 546-560.

Thuburn, J., Ringler, T. D., Skamarock, W. C., Klemp, J. B., Dec. 2009. Numerical representation of geostrophic modes on arbitrarily structured C-grids. Journal of Computational Physics 228, 8321-8335.

Tseng, Y.-H., Dietrich, D. E., 2006. Entrainment and transport in idealized threedimensional gravity current simulation. Journal of Atmospheric and Oceanic Technology 23 (9), 1249-1269.

Turner, J., 1986. Turbulent entrainment: the development of the entrainment assumption, and its application to geophysical flows. Journal of Fluid Mechanics 173, 431-471. 
von Appen, W.-J., Pickart, R. S., Brink, K. H., Haine, T. W., 2014. Water column structure and statistics of denmark strait overflow water cyclones. Deep Sea Research Part I: Oceanographic Research Papers 84, 110-126.

Wang, Q., Danilov, S., Schröter, J., 2008. Comparison of overflow simulations on different vertical grids using the finite element ocean circulation model. Ocean Modelling 20 (4), 313-335.

Willems, R., 1995. Experiment evaluates ocean models and data assimilation in the gulf stream. Oceanographic Literature Review 42 (5), 322-323.

Winton, M., Hallberg, R., Gnanadesikan, A., 1998. Simulation of density-driven frictional downslope flow in z-coordinate ocean models. Journal of Physical Oceanography 28 (11), 2163-2174.

Xu, X., Chang, Y. S., Peters, H., Özgökmen, T. M., Chassignet, E. P., 2006. Parameterization of gravity current entrainment for ocean circulation models using a high-order 3d nonhydrostatic spectral element model. Ocean Modelling 14 (1), 19-44. 